\title{
Markerless gene knockout and integration to express heterologous biosynthetic gene clusters in Pseudomonas putida
}

Choi, Kyeong Rok; Cho, Jae Sung; Cho, In Jin; Park, Dahyeon; Lee, Sang Yup

Published in:

Metabolic Engineering

Link to article, DOI:

10.1016/j.ymben.2018.05.003

Publication date:

2018

Document Version

Peer reviewed version

Link back to DTU Orbit

Citation (APA):

Choi, K. R., Cho, J. S., Cho, I. J., Park, D., \& Lee, S. Y. (2018). Markerless gene knockout and integration to express heterologous biosynthetic gene clusters in Pseudomonas putida. Metabolic Engineering, 47, 463-474. https://doi.org/10.1016/j.ymben.2018.05.003

\section{General rights}

Copyright and moral rights for the publications made accessible in the public portal are retained by the authors and/or other copyright owners and it is a condition of accessing publications that users recognise and abide by the legal requirements associated with these rights.

- Users may download and print one copy of any publication from the public portal for the purpose of private study or research.

- You may not further distribute the material or use it for any profit-making activity or commercial gain

- You may freely distribute the URL identifying the publication in the public portal 


\section{Author's Accepted Manuscript}

Markerless gene knockout and integration to express heterologous biosynthetic gene clusters in Pseudomonas putida

Kyeong Rok Choi, Jae Sung Cho, In Jin Cho, Dahyeon Park, Sang Yup Lee

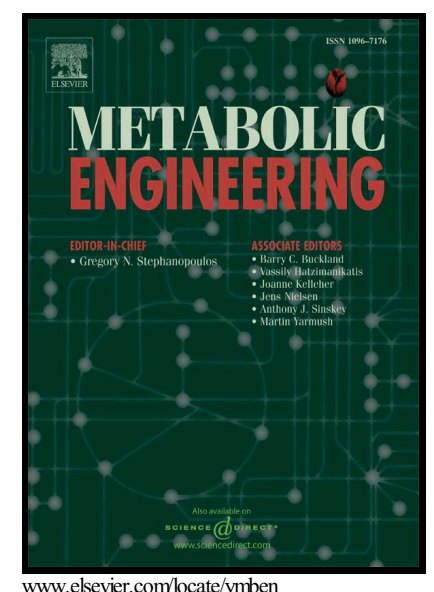

PII: S1096-7176(18)30166-6

DOI: $\quad$ https://doi.org/10.1016/j.ymben.2018.05.003

Reference: YMBEN1401

To appear in: Metabolic Engineering

Received date: 20 April 2018

Revised date: 5 May 2018

Accepted date: 6 May 2018

Cite this article as: Kyeong Rok Choi, Jae Sung Cho, In Jin Cho, Dahyeon Park and Sang Yup Lee, Markerless gene knockout and integration to express heterologous biosynthetic gene clusters in Pseudomonas putida, Metabolic Engineering, https://doi.org/10.1016/j.ymben.2018.05.003

This is a PDF file of an unedited manuscript that has been accepted for publication. As a service to our customers we are providing this early version of the manuscript. The manuscript will undergo copyediting, typesetting, and review of the resulting galley proof before it is published in its final citable form. Please note that during the production process errors may be discovered which could affect the content, and all legal disclaimers that apply to the journal pertain. 


\section{Markerless gene knockout and integration to express heterologous biosynthetic gene clusters in Pseudomonas putida}

Kyeong Rok Choi ${ }^{\mathrm{a}}$, Jae Sung Cho ${ }^{\mathrm{a}}$, In Jin Cho ${ }^{\mathrm{a}}$, Dahyeon Park ${ }^{\mathrm{a}} \&$ Sang Yup Lee ${ }^{\mathrm{a}, \mathrm{b}, *}$

${ }^{a}$ Metabolic and Biomolecular Engineering National Research Laboratory, Department of Chemical and Biomolecular Engineering (BK21 Plus Program), BioProcess Engineering Research Center, BioInformatics Research Center, and Institute for the BioCentury, Korea Advanced Institute of Science and Technology, 291, Daehak-ro, Yuseong-gu, Daejeon, 34141, Republic of Korea.

${ }^{\mathrm{b}}$ The Novo Nordisk Foundation Center for Biosustainability, Technical University of Denmark, Kongens Lyngby, Denmark

*Correspondence should be addressed to S.Y.L. (leesy@kaist.ac.kr) 


\section{ACCEPTED MANUSCRIPT}

\section{Abstract}

Pseudomonas putida has gained much interest among metabolic engineers as a workhorse for producing valuable natural products. While a few gene knockout tools for $P$. putida have been reported, integration of heterologous genes into the chromosome of $P$. putida, an essential strategy to develop stable industrial strains producing heterologous bioproducts, requires development of a more efficient method. Current methods rely on time-consuming homologous recombination techniques and transposon-mediated random insertions. Here we report a RecET recombineering system for markerless integration of heterologous genes into the $P$. putida chromosome. The efficiency and capacity of the recombineering system were first demonstrated by knocking out various genetic loci on the $P$. putida chromosome with knockout lengths widely spanning 0.6 to $101.7 \mathrm{~kb}$. The RecET recombineering system developed here allowed successful integration of biosynthetic gene clusters for four proof-ofconcept bioproducts, including protein, polyketide, isoprenoid, and amino acid derivative, into the target genetic locus of $P$. putida chromosome. The markerless recombineering system was completed by combining Cre/lox system and developing efficient plasmid curing systems, generating final strains free of antibiotic markers and plasmids. This markerless recombineering system for efficient gene knockout and integration will expedite metabolic engineering of $P$. putida, a bacterial host strain of increasing academic and industrial interest.

Graphical abstract 


\section{ACCEPTED MANUSCRIPT}

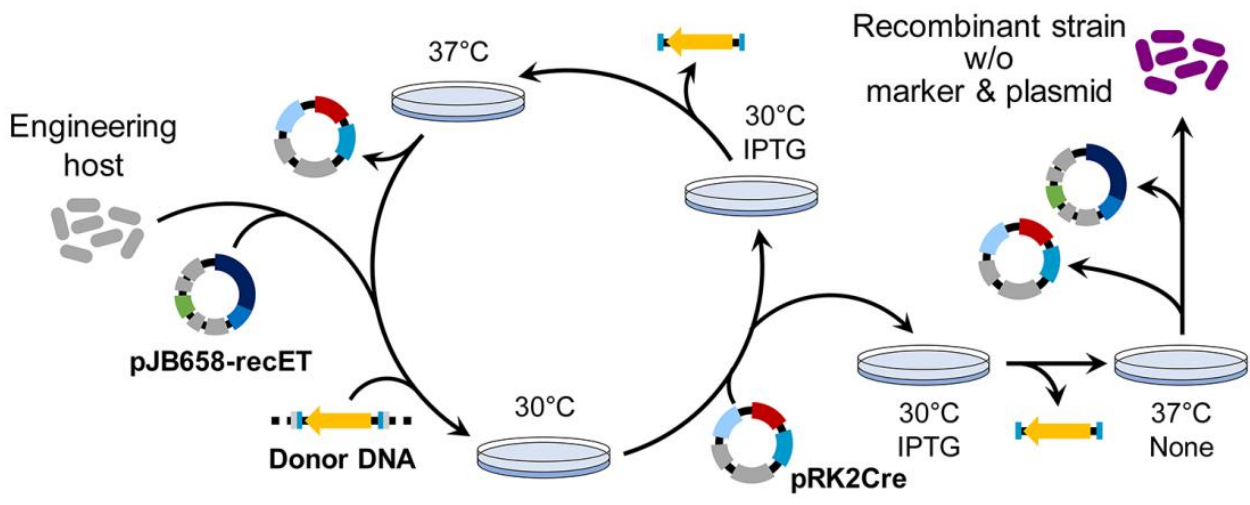

Keywords: Pseudomonas putida; Recombineering; RecET; Cre/lox; Gene knockout; Gene integration 


\section{ACCEPTED MANUSCRIPT}

\section{Introduction}

Pseudomonas putida, a Gram-negative soil bacterium, has recently attracted much attention as a microbial cell factory for the production of valuable chemicals due to its robustness (Nikel et al., 2016; Nikel et al., 2014; Poblete-Castro et al., 2012). The versatile metabolism of $P$. putida empowers this bacterium as a producer of not only industrial bulk chemicals but also diverse natural products, including rhamnolipids, isoprenoids, polyketides, non-ribosomal peptides, and amino acid-derived secondary metabolites (Loeschcke and Thies, 2015). In addition, $P$. putida KT2440, officially classified as a generally recognized as safe (GRAS) strain (Federal Register, 1982), is ideal in diverse applications, especially for the production of value-added secondary metabolites for human uses.

Several genetic engineering strategies have been devised to facilitate the engineering of P. putida (Martinez-Garcia and de Lorenzo, 2017). Traditional homologous recombination technologies have been applied to knockout genes in $P$. putida using counterselection markers, including the sacB, pyrF, and upp genes (Galvao and de Lorenzo, 2005; Graf and Altenbuchner, 2011; Gross et al., 2006; Johnson et al., 2017), and site-specific recombinases such as Cre/lox and Flp/FRT systems have also been examined to facilitate markerless gene knockout (Ibrahim et al., 2015; Leprince et al., 2012). A meganuclease I-SceI is another component used to facilitated scarless knockout of genes (Chen et al., 2016; Martinez-Garcia and de Lorenzo, 2011; Martinez-Garcia et al., 2014). Recently, recombineering systems using Ssr protein derived from $P$. putida DOT-T1E (Aparicio et al., 2016) and $\lambda$ Red system derived from Escherichia coli bacteriophage $\lambda$ (Luo et al., 2016) were applied for recombineering of P. putida. Moreover, clustered regularly interspaced palindromic repeat (CRISPR)/CRISPRassociated (Cas) systems coupled with the recombineering systems were used to further 
enhance the efficiency of genome editing in P. putida (Aparicio et al., 2017; Cook et al., 2018; Sun et al., 2018). However, very few studies reported deletions of large genomic fragments (Aparicio et al., 2017; Martinez-Garcia et al., 2014), while reduced genome size of P. putida improves its performance as a heterologous expression host (Lieder et al., 2015). More importantly, the integration of heterologous genes into the $P$. putida chromosome still relies on the outdated homologous recombination using selection markers (Cao et al., 2012; Gong et al., 2016; Gross et al., 2006; Wenzel et al., 2005) and random insertion using transposon (Chai et al., 2012; Domrose et al., 2015; Domrose et al., 2017; Glandorf et al., 2001; Loeschcke et al., 2013) after conjugation, while the reconstruction of the heterologous BGCs in $E$. coli cloning hosts itself has been facilitated by recombineering strategies including Red/ET cloning.

Plasmid-borne expression of heterologous biosynthetic genes have a potential risk of strain instability during fermentation processes in the bioindustry (Lee and Kim, 2015). Furthermore, the addition of antibiotics often employed to maintain plasmids during fermentation complicates the downstream purification processes, particularly for the production of value-added natural products for human uses. Thus, the construction of markerand plasmid-free metabolically engineered host for the production of heterologous natural products is important, especially for recombinant $P$. putida KT2440 strains of which the advantage of use comes from being their GRAS status. However, the majority of heterologous natural products requires biosynthetic gene clusters (BGCs) larger than $6 \mathrm{~kb}$ (Loeschcke and Thies, 2015), complicating integration of the BGCs to the chromosome using current recombineering tools. Thus, we exploited new recombineering strategies to substitute the traditional homologous recombination/transposon-based methods coupled with 


\section{ACCEPTED MANUSCRIPT}

conjugation and overcome the inefficiencies in constructing marker/plasmid-free recombinant P. putida strains producing natural products.

Recombineering utilizes recombinases and their associated proteins to facilitate homology-based recombination between target DNA and donor DNA (Copeland et al., 2001). The recombinases and associated proteins generate a single-stranded region on the donor DNA and invade the target DNA while stabilizing the single-stranded regions of DNAs (Noirot and Kolodner, 1998). Among two most famous $\lambda$ Red and RecET recombineering systems derived from $E$. coli bacteriophage $\lambda$ and $E$. coli Rac prophage, respectively, only $\lambda$ Red system has been examined in P. putida (Chen et al., 2016; Cook et al., 2018; Sun et al., 2018). In addition, another system using Ssr protein, which is a newly identified homolog of the recombinase Bet from the $\lambda$ Red system, was reported (Aparicio et al., 2016). Although both recombinases Bet and RecT of $\lambda$ Red and RecET systems respectively possess doublestranded DNA (dsDNA) invasion activity, Bet requires low GC content (20\%) for invasion (Rybalchenko et al., 2004) while RecT is independent of the GC content for invasion (Noirot and Kolodner, 1998). Considering P. putida is a bacterium with a high GC content (61.6\% in average for $P$. putida KT2440), the recombineering capacity of RecET system from $E$. coli Rac prophage should be examined in P. putida, as higher performance is expected.

In this work, we report the development of RecET recombineering system for markerless engineering of $P$. putida. We prove the recombineering capacity of the new system by knocking out multiple genes and large gene clusters. Subsequently, we develop an efficient system for markerless integration of heterologous BGCs as proof-of-concept examples. 


\section{ACCEPTED MANUSCRIPT}

\section{Materials and Methods}

\subsection{Strains and Media}

The bacterial strains used in this study are listed in Table S1. E. coli DH5 $\alpha$ was used for general gene works. E. coli strains were grown in Luria-Bertani (LB) medium (10 g/L tryptone, $5 \mathrm{~g} / \mathrm{L}$ yeast extract, and $10 \mathrm{~g} / \mathrm{L} \mathrm{NaCl}$ ) or LB agar (LB supplemented with $1.5 \%$ agar) at $30^{\circ} \mathrm{C}$ or $37^{\circ} \mathrm{C}$. P. putida strains were grown in $\mathrm{LB}$ medium with $5 \mathrm{~g} / \mathrm{L} \mathrm{NaCl}(\mathrm{LB}(5 \mathrm{~g} / \mathrm{L}$ $\mathrm{NaCl})$ ) or $\mathrm{LB}$ agar at $30^{\circ} \mathrm{C}$. Antibiotics, when needed, were supplemented at the following concentrations: for E. coli, $50 \mu \mathrm{g} / \mathrm{mL}$ ampicillin (Ap), $25 \mu \mathrm{g} / \mathrm{mL}$ kanamycin (Km), 100 $\mu \mathrm{g} / \mathrm{mL}$ spectinomycin (Sm), and $10 \mu \mathrm{g} / \mathrm{mL}$ tetracycline (Tc); for P. putida, $500 \mu \mathrm{g} / \mathrm{mL}$ Ap, 50 $\mu \mathrm{g} / \mathrm{mL} \mathrm{Km}$, and $50 \mu \mathrm{g} / \mathrm{mL}$ Tc.

\subsection{Construction of RecET vectors}

All plasmids used in this study are listed in Table S1. All primer series $\mathrm{P}^{*}$ used to construct vectors are listed in Table S2 with corresponding template for polymerase chain reaction (PCR). To construct stable expression vector replicable in P. putida, EcoRI site in plasmid pTac15K was substituted with BamHI site by amplifying plasmid pTac15K with primers P1/P2 and self-assembly by Gibson assembly (Gibson et al., 2009), constructing plasmid pTac15KEco2Bam. The expression unit in plasmid pTac15KEco2Bam was amplified with primers P3/P4 and assembled with DNA fragment amplified from plasmid pBBR1MCS2 with primers P5/P6, generating plasmid pBBR1TacK0. Subsequent cloning of a lac $I^{Q}$ fragment amplified from plasmid pTrc99A using primers P7/P8 into plasmid pBBR1TacK0

digested with AgeI by Gibson assembly (Gibson et al., 2009) resulted in plasmid 


\section{ACCEPTED MANUSCRIPT}

pBBR1TacKI0.

To minimize leaky expression, a tightly regulable expression vector pBBR1mKSMCS harboring $\mathrm{P}_{\mathrm{m}} / \mathrm{XylS}$ promoter/regulator system in $P$. putida was constructed. $\mathrm{P}_{\mathrm{m}}$ and $x y l S$ genes were amplified from genomic DNA (gDNA) of $P$. putida mt-2 harboring plasmid pWW0 with primer sets $\mathrm{P} 9 / \mathrm{P} 10$ and $\mathrm{P} 11 / \mathrm{P} 12$, respectively. The two fragments were assembled into a single DNA fragment by overlapping PCR with primers P10/P12 using a mixture of the two DNA fragments as templates. The amplified product was assembled by Gibson assembly together with a DNA fragment amplified from plasmid pBBR1TacKI0 using primers $\mathrm{P} 13 / \mathrm{P} 14$, constructing plasmid pBBR1mKS-MCS.

To construct a plasmid expressing E. coli $\mathrm{K}-12$ MG1655 recET genes, under the regulation of $\mathrm{Pm} / \mathrm{XylS}$ system in $P$. putida, the recET genes were amplified from gDNA of $E$. coli MG1655 using primers P15/P16. The amplified product was assembled with plasmid pBBR1mKS-MCS digested with NdeI and HindIII by Gibson assembly (Gibson et al., 2009), constructing plasmid pBBR1mKS-recET.

To construct a more stable RecET vector, the recET genes amplified from the gDNA of E. coli MG1655 with primers P15/P17 was assembled with another DNA fragment amplified from plasmid pJB658 with primers P10/P18 by Gibson assembly (Gibson et al., 2009), constructing plasmid pJB658-recET. Similarly, the $r e c E$ and $r e c T$ genes were amplified from the gDNA of E. coli MG1655 with primers P19/P20 and P21/P22, respectively. The amplified DNA fragments were assembled with the DNA fragment amplified from plasmid pJB658 with primers P10/P18 by Gibson assembly (Gibson et al., 2009), constructing plasmid pJB658-recTE.

To construct a temperature-sensitive RecET vector, the trfAts gene was amplified 


\section{ACCEPTED MANUSCRIPT}

from plasmid pSIM9 (Datta et al., 2006) using primers P23/P24. The amplified fragment and plasmid pJB658-recET were digested with HindIII and PvuII and ligated to each other, constructing plasmid pJB658ts-recET.

\subsection{Construction of Cre vectors}

A Cre vector for P. putida was constructed based on plasmid pJB658 (Blatny et al., 1997). Briefly, lacI-cre fragment was amplified from plasmid pJW168 using primers P25/P26 and pJB658 was amplified using primers P27/P28. The amplified DNA fragments were digested using $X m a \mathrm{I}$ and $\mathrm{XhoI}$ and joined to each other by ligation, constructing plasmid pCreRK2A.

To construct a temperature-sensitive Cre vector, a temperature-sensitive origin of replication RK2ts, Km resistance gene aph(3')-I, and lacI-cre fragment were amplified from plasmids pSIM9 (Datta et al., 2006), pTac15K (Lee et al., 2008), and pJW168 (Wild et al., 1998) using primers $\mathrm{P} 29 / \mathrm{P} 30, \mathrm{P} 31 / \mathrm{P} 32$, and $\mathrm{P} 8 / \mathrm{P} 25$, respectively. The three amplified fragment were assembled with each other by Gibson assembly (Gibson et al., 2009), constructing plasmid pRK2Cre.

\subsection{Construction of template and donor vectors for recombineering}

To construct a template vector harboring lox71-tetA $(C)$-lox66 cassette used to prepare linear donor DNA for recombineering, tetA $(C)$ gene from plasmid pLyc184 (Choi et al., 2010) was amplified using primers P33/P34, and plasmid pECmulox (Kim et al., 2008) without cat gene was amplified using primers P35/P36. The two amplified DNA fragments were 
assembled by Gibson assembly (Gibson et al., 2009), constructing plasmid pTetAmulox.

To construct a donor vector for knocking out the $p v d D$ gene of $P$. putida KT2440, the lox71-tet $A(C)$-lox66 cassette, the $s a c B$ gene, and a pair of 1-kb fragments homologous to the $p v d D$ gene (homology arms) were assembled together with the pMB1 origin, which does not initiate replication in $P$. putida KT2440. Briefly, the $s a c B$ gene and pMB1 origin of replication were amplified from plasmids pSKH120 and pTetAmulox using primers P37/P38 and P39/P40, respectively. Subsequently, sacB-ori fragment was amplified from the mixture of the two amplified fragments using primers P37/P39. Similarly, left and right homology arms for the $p v d D$ gene were amplified from the gDNA of $P$. putida KT2440 using primer sets $\mathrm{P} 41 / \mathrm{P} 42$ and $\mathrm{P} 43 / \mathrm{P} 44$, respectively. The $\operatorname{lox} 71$-tetA $(C)$-lox66 cassette was amplified from plasmid pTetAmulox using primers $\mathrm{P} 45 / \mathrm{P} 46$. Subsequently, $\Delta p v d D:: \operatorname{lox} 71$-tetA(C)-lox66 fragment was amplified from the mixture of the latter three fragments using primers P47/P48, followed by assembly with the sacB-ori fragment by Gibson assembly (Gibson et al., 2009), constructing plasmid pTetSac- $\Delta$ pvdD.

Based on the plasmid pTetSac- $\Delta \mathrm{pvdD}$, platform vectors for the heterologous gene integration was constructed. To construct a integration platform vector for $P$. putida KT2440, plasmid pTetSac- $\Delta$ pvdD was amplified with primers P49/P50 and self-assembled by Gibson assembly (Gibson et al., 2009), constructing plasmid pTetSac- $\Delta$ pvdD::Adaptor harboring multiple cloning sites for cloning heterologous genes.

To construct integration donor vectors for $P$. putida, the egfp gene and biosynthetic genes for flaviolin, lycopene, and violacein were cloned into the plasmid pTetSac$\Delta$ pvdD::Adaptor. Briefly, the $e g f p$ gene was amplified from plasmid pTacCC1-EGFP (Cho et al., 2017) using primers P51/P52. The rppA gene for the biosynthesis of flaviolin was 


\section{ACCEPTED MANUSCRIPT}

amplified from the genomic DNA of Streptomyces griseus using primers P53/P54. The crtEIB genes for the biosynthesis of lycopene were amplified from plasmid pLyc184 (Choi et al., 2010) using primers P55/P56. The vioABCDE genes for the biosynthesis of violacein were amplified into two fragments. The upstream part of the violacein biosynthetic gene cluster (Vio-1) was amplified from the genomic DNA of Chromobacterium violaceum using primers P57/P58 followed by second round amplification using primers P59/P60. The downstream part of the violacein biosynthetic gene cluster (Vio-2) was amplified from the genomic DNA of $C$. violaceum using primers P61/P62. The amplified $e g f p$ gene and flaviolin biosynthetic genes were digested with $M l u \mathrm{I}$ and individually ligated to the plasmid pTetSac$\Delta \mathrm{pvdD}:$ :Adaptor digested with the same restriction endonuclease, constructing plasmids pTetSac- $\Delta$ pvdD::EGFP, pTetSac- $\Delta$ pvdD::Flaviolin. The amplified lycopene biosynthetic genes were digested with ApaI and ligated to the integration platform vectors digested with the same restriction endonuclease, constructing plasmid pTetSac- $\Delta \mathrm{pvdD}:$ :Lycopene. Finally,

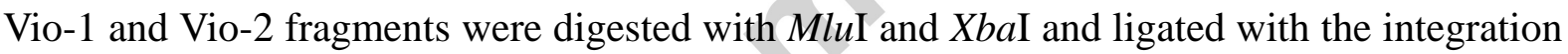
platform vectors digested with $M l u \mathrm{I}$, constructing plasmid pTetSac- $\Delta \mathrm{pvdD}:$ Violacein.

\subsection{Preparation of DNA fragments for recombineering}

Primer series del_* used to amplify DNA fragments for recombineering and the resulting linear donor dsDNAs are listed in Table $\mathrm{S} 3$. The Tc resistance gene $\operatorname{tet} A(C)$ flanked by a pair of 50-bp homologies to the $p v d D$ gene of $P$. putkda KT2440 ( $\Delta$ pvdD1k50::tetA) was amplified from plasmid pLyc184 (Choi et al., 2010) using primers del_pvdD1k-TcR+ and del_pvdD1k-TcR-. The second round amplification using primers del_pvdD1-60k++ and del_pvdD1k-- appended additional 50-bp homologies to each end of the fragment 


\section{ACCEPTED MANUSCRIPT}

( $\Delta$ pvdD1k100::tetA). The aph(3')-IIa gene, the Km resistance gene, with 100-bp homologies to the $p v d D$ gene of $P$. putida KT2440 ( $\Delta$ pvdD1k100::aph) was amplified from plasmid pBBR1MCS-2 using primers del_pvdD1k-Km+ and del_pvdD1k-Km- followed by the second round amplification using primers del_pvdD1k++ and del_pvdD1k--. Similarly, lox71-tetA $(C)$-lox66 cassette for knocking out gene * was amplified from plasmid pTetAmulox using primer series del_*-lox71+ and del_*-lox66- (Table S3) followed by the second round amplification using primers del_*++ and del_*-- (Table S3), generation the knockout fragment $\Delta^{*} 100:$ :tetA-lox.

\subsection{Transformation of P. putida}

P. putida strains were routinely transformed with plasmids by a modified version of a previously described electroporation method (Iwasaki et al., 1994). Briefly, overnight culture of $P$. putida cells was washed twice with $300 \mathrm{mM}$ sucrose or $10 \%$ glycerol and resuspended to the same solution at room temperature. The resulting competent cell was mixed with plasmid DNA to be introduced, and an electric pulse of 1.8 or $2.5 \mathrm{kV}$ with capacitance of 25 $\mu \mathrm{F}$ and resistance of $200 \Omega$ was applied in 1- or 2-mm electroporation cuvette (Hi-Lab, Taiwan), respectively, using Gene Pulser® II (Bio-Rad, USA). The electroporated cell was recovered in $\mathrm{LB}(5 \mathrm{~g} / \mathrm{L} \mathrm{NaCl})$ medium at $30^{\circ} \mathrm{C}$ for $2 \mathrm{~h}$ with shaking at $200 \mathrm{rpm}$ and plated on LB agar plate with proper antibiotics.

For recombineering, recombinant $P$. putida strains harboring RecET vector were precultured in $\mathrm{LB}(5 \mathrm{~g} / \mathrm{L} \mathrm{NaCl})$ medium with appropriate antibiotics, and $1 \mathrm{~mL}$ of the culture was transferred to $50 \mathrm{~mL} \mathrm{LB}(5 \mathrm{~g} / \mathrm{L} \mathrm{NaCl})$ medium in 250-mL Erlenmeyer flask supplemented with $5 \mathrm{mM} m$-toluic acid and proper antibiotics. The cells were incubated at 


\section{ACCEPTED MANUSCRIPT}

$30^{\circ} \mathrm{C}$ with $200 \mathrm{rpm}$ shaking until the optical density of the cells at $600 \mathrm{~nm}\left(\mathrm{OD}_{600}\right)$ reaches around 2, ice-chilled, and harvested from $49 \mathrm{~mL}$ of the culture broth by centrifugation at $2,090 \times \mathrm{g}$ at $4^{\circ} \mathrm{C}$. The resulting pellet was washed twice with $300 \mathrm{mM}$ sucrose solution and resuspended to $200 \mu \mathrm{L}$ of $300 \mathrm{mM}$ sucrose solution for each $\mathrm{OD}_{600}$ unit of the cultured cell. For example, cell pellet harvested from $49 \mathrm{~mL}$ of the culture with $\mathrm{OD}_{600}=2.00$ was resuspended to $400 \mu \mathrm{L}(=2.00 \times 200 \mu \mathrm{L})$ of $300 \mathrm{mM}$ sucrose solution. The fresh $70-\mu \mathrm{L}$ aliquot of the resuspended cells were mix with recombineering donor DNA in the form of either linear dsDNA $(3 \mu \mathrm{g})$ or plasmid DNA $(1 \mu \mathrm{g})$ and applied for $1.8 \mathrm{-kV}$ electric pulse with capacitance of $25 \mu \mathrm{F}$ and resistance of $200 \Omega$ using Gene Pulser ${ }^{\circledR}$ II (Bio-Rad, USA) in 1mm gap cuvette (Hi-Lab, Taiwan). The resulting transformants were recovered in $900 \mu \mathrm{L}$ of LB $(5 \mathrm{~g} / \mathrm{L} \mathrm{NaCl})$, statically incubated at $30^{\circ} \mathrm{C}$ for $2 \mathrm{~h}$, and plated on LB agar plate with appropriate antibiotics and incubated at $30^{\circ} \mathrm{C}$.

\subsection{Expression test}

The expression of the proteins of interest in recombinant $P$. putida strains was examined by SDS-PAGE after induction. Briefly, recombinant $P$. putida strains were precultured in $5 \mathrm{~mL} \mathrm{LB}(5 \mathrm{~g} / \mathrm{L})$ with appropriate antibiotics at $30^{\circ} \mathrm{C}$ with $200 \mathrm{rpm}$ of shaking and transferred to the same medium supplemented with inducer. The resulting cells were lysed by sonication and the resulting cell lysate were further analyzed by SDS-PAGE.

\subsection{Plasmid curing}

Recombinant $P$. putida strains free of plasmids were isolated plasmid curing. To 


\section{ACCEPTED MANUSCRIPT}

obtain $P$. putida strains cured of the RecET vector, the recombinant strains harboring the RecET vectors were streaked on LB-agar plate free of antibiotics and incubated at $30^{\circ} \mathrm{C}$, unless mentioned otherwise. To cure the Cre vector, the recombinant strain harboring the Cre vector was streaked on LB-agar plate free of antibiotics and incubated at $37^{\circ} \mathrm{C}$, unless mentioned otherwise. Two vectors could be simultaneously cured by streaking the strain on LB-agar plate free of antibiotics followed by incubation at $37^{\circ} \mathrm{C}$. Curing of the plasmids were confirmed by testing the antibiotic sensitivity of the recombinant strains on LB-agar plates supplemented with corresponding antibiotics.

\subsection{Markerless recombineering}

To knockout endogenous genes or integrate heterologous genes into the chromosome of $P$. putida, competent cells for recombineering were transformed with either of donor dsDNA series $\Delta^{*} 100:$ :tetA-lox (Table S3) or donor plasmid series pTetSac- $\Delta$ pvdD::* (Table S1) and plated on LB-agar supplemented with Tc or LB ( $0 \mathrm{~g} / \mathrm{L} \mathrm{NaCl})$-agar supplemented with Tc and $10 \%$ sucrose, respectively. After incubation at $30^{\circ} \mathrm{C}$, integration of $\operatorname{tet} A(C)$ gene at the target genomic loci were examined by colony PCR using primer series chk_* listed in Table S4. Positive mutants were transformed with Cre vectors (plasmid pCreRK2A or pRK2Cre) and plated on LB-agar plates supplemented with $1 \mathrm{mM}$ IPTG and appropriate antibiotic (Ap or $\mathrm{Km}$, respectively). Excision of the $\operatorname{tet} A(C)$ gene in each colony was examined by making master plates by sequentially streaking the colonies on two LB-agar plates respectively supplemented with Tc and no antibiotic with subsequent observation of the Tc sensitivity of the strains. Markerless recombineering was doubly confirmed by colony PCR using primers listed in Table S4. To prepare strains cured of the RecET and Cre vectors, Tc-sensitive mutant 


\section{ACCEPTED MANUSCRIPT}

strains from the master plate without antibiotic were streaked on another fresh LB-agar plate without antibiotic and incubated at $37^{\circ} \mathrm{C}$ to generate single colonies. Curing of the RecET and Cre vectors were examined by sequentially streaking the resulting single colonies on three LB-agar plates supplemented with Ap, Km, and no antibiotic, respectively, and observing the antibiotic susceptibility of the strains after overnight incubation at $30^{\circ} \mathrm{C}$.

\subsection{Motility test}

To examine the motility of mutant $P$. putida KT2440 strains with the deletion of 69.3-kb or 101.7-kb region including the flagellar gene cluster, the wild-type and the mutant P. putida KT2440 strains were inoculated into $5 \mathrm{~mL} \mathrm{LB}(5 \mathrm{~g} / \mathrm{L} \mathrm{NaCl})$ medium and incubated at $30^{\circ} \mathrm{C}$ with $200 \mathrm{rpm}$ of shaking for overnight. $\mathrm{LB}(5 \mathrm{~g} / \mathrm{L} \mathrm{NaCl})$-agar plate containing $0.3 \%$ (w/v) agar was inoculated with the overnight culture using sterile toothpick and incubated at $30^{\circ} \mathrm{C}$ after sealing the plate to prevent dehydration. The spread of the colonies on the plate were observed to measure the motility of each strain.

\subsection{Scanning electron microscopy}

The morphological change of the mutant strains were observed by scanning electron microscopy. To prepare samples, $P$. putida strains were cultured in LB $(5 \mathrm{~g} / \mathrm{L} \mathrm{NaCl})$ for overnight, washed with distilled water, and resuspended in distilled water. The cell suspension was dried onto silicon wafer and shadowed with osmium at an angle of $20^{\circ}$ before examination with FEI Magellan 400 scanning electron microscope (FEI company, USA). 


\section{ACCEPTED MANUSCRIPT}

\section{Results and discussion}

\subsection{Construction of functional RecET expression system for P. putida}

As with our previous experiences in engineering the recT gene (Cho et al., 2017), leaky expression of the recT gene from the Ptac/LacI ${ }^{\mathrm{Q}}$ system interfered cloning of the recT gene in $E$. coli cloning hosts. Since $\mathrm{P}_{\mathrm{m}} / \mathrm{XylS}$ system was demonstrate to be tighter in gene expression regulations (Balzer et al., 2013), we constructed plasmid pBBR1mKS-recET expressing the recET genes under the regulation of the $\mathrm{P}_{\mathrm{m}} / \mathrm{XylS}$ system (Table $\mathrm{S} 1$ ). To investigate the recombineering capacity of the RecET vector, knockout of the $p v d D$ gene encoding pyoverdine synthase, which is involved in the biosynthesis of a siderophore pyoverdine with green fluorescence, was examined in recombinant $P$. putida KT2440 strain harboring plasmid pBBR1mKS-recET (Table S1). Induction of the strain with $m$-toluic acid followed by transformation with linear donor dsDNA fragment encoding the Tc resistance gene tetA $(C)$ and a pair of 100-bp homologies to the pvdD gene ( $\Delta$ pvdD100::tetA) (Table S3) resulted in a single colony resistant to Tc with the $p v d D$ gene knocked out. In the subsequent trials to optimize the recombineering method, however, no additional colony with the $p v d D$ gene knockout could be isolated, inferring inferior performance of the RecET vector.

Speculating the weak expression of the recET gene from plasmid pBBR1mKS-recET, expression levels of the RecE and RecT proteins were examined by SDS-PAGE. As hypothesized, protein bands corresponding to the expected sizes of the RecE and RecT proteins (96.4 and $29.7 \mathrm{kDa}$, respectively) were not prominent (Fig. S1b). Assuming higher expression level of RecT protein is required to achieve reproducibility and high efficiency in recombineering, a new RecET vector pJB658-recET was constructed (Fig. 1a and Table S1). In addition, plasmid pJB658-recTE harboring the recT gene before the recE gene was 


\section{ACCEPTED MANUSCRIPT}

constructed (Fig. 1b and Table S1) in effort to further enhance the expression level of the recT gene. After transforming P. putida KT2440 with the two new plasmids, significant expression of the RecT protein was observed in both of the strains upon induction with $m$-toluic acid (Fig. 1c). Unexpectedly, however, the reordering of the $\operatorname{rec} T$ gene before the $\operatorname{rec} E$ gene had no positive effect on the expression level of the recT gene; rather, the original recET operon resulted in slightly higher expression of the RecT protein. Thus, the plasmid pJB658-recET was chosen for the following test for the recombineering in P. putida KT2440. In addition, the knockout of the $p v d D$ gene with plasmid pJB658-recET was reproducible in subsequent trials, supporting our assumption that the high level of recombinase expression is critical in recombineeing.

\subsection{Optimization of the RecET recombineering system}

The efficiency of integrating heterologous genes into the chromosome by recombineering has been reported to decrease as the size of the DNA insertion increases (Kuhlman and Cox, 2010). Therefore, parameters for high recombineering efficiency need evaluation to develop a highly efficient recombineering system applicable for large BGC integration. To screen the optimal inducer concentration and cell harvest time point after induction, the recombinant KT2440-recET strain harboring the plasmid pJB658-recET (Table S1) was sampled at multiple time points (measured by $\mathrm{OD}_{600}$ ) during the cultivation in $50 \mathrm{~mL}$ LB (5 g/L NaCl) medium supplemented with 0,2 , and $5 \mathrm{mM} m$-toluic acid (Fig. S1c-e). Protein expression profiles of the sampled cells showed significant overexpression of the RecT protein upon the addition of the inducer (Fig. S1c-e), yet no significant differences were observed between the cells induced with 2 and $5 \mathrm{mM} m$-toluic acid (Fig. S1f). Thus, 5 
$\mathrm{mM} m$-toluic acid was chosen for the induction concentration of KT2440-recET strain to prepare competent cells in the subsequent recombineering experiments.

In contrast to the no significant effect of inducer concentration on the RecT protein level, higher cell density $\left(\mathrm{OD}_{600}\right)$, which was used to determine the cell harvest time point, showed strong correlation with the higher RecT protein level (Fig. S1d-f), suggesting higher recombineering efficiencies for competent cells harvested at higher $\mathrm{OD}_{600}$. Considering the transformation efficiency itself, however, bacterial cells in the early exponential phase, rather than the stationary phase, is generally accepted to be a more optimal time point to prepare competent cells, as many protocols for preparing competent cells recommend harvesting bacterial cells in their early exponential phase (Iwasaki et al., 1994; Ren et al., 2017; Ruan et al., 2015; Tu et al., 2016). To find the optimal time point between the two opposite tendencies, the recombinant KT2440-recET strain was cultured in $50 \mathrm{~mL} \mathrm{LB}(5 \mathrm{~g} / \mathrm{L} \mathrm{NaCl})$ supplemented with $5 \mathrm{mM} m$-toluic acid, and competent cells for recombineering were prepared at different $\mathrm{OD}_{600}$ points while resuspending the cells to same final cell density (see Section 2.6 for details). Subsequent recombineering using the donor dsDNA $\Delta$ pvdD1k100::tetA (Table S3) resulted in more colonies with competent cells made at higher $\mathrm{OD}_{600}$ (Fig. 2a), while all of the colonies appeared harbored the $p v d D$ gene knocked out. Thus, the recombinant KT2440recET strain was induced with $5 \mathrm{mM} m$-toluic acid was harvested at $\mathrm{OD}_{600} \sim 2$ in the following competent cell preparation for recombineering. Further screening of the recovery temperature indicated no significant difference in recombineering efficiencies comparing $30^{\circ} \mathrm{C}$ and $37^{\circ} \mathrm{C}$ (Fig. 2b), and the knockout of the $p v d D$ gene using the donor dsDNAs $\Delta$ pvdD1k100::tetA and $\Delta$ pvdD1k100::aph, which harbors the aph(3')-IIa gene responsible for $\mathrm{Km}$ resistance (Table S3), resulted in similar recombineering efficiency (Fig. 2c). All of 


\section{ACCEPTED MANUSCRIPT}

the colonies formed after recombineering harbored positive mutations on the $p v d D$ gene. In summary, $5 \mathrm{mM} m$-toluic acid was used to induce RecET-expressing $P$. putida strains, the cells were harvested at $\mathrm{OD}_{600} \sim 2$ to prepare competent cells, and the cells were recovered at $30^{\circ} \mathrm{C}$ after electroporation for subsequent recombineering experiments.

\subsection{Establishing a strategy for RecET vector curing}

The RecET vector should be eliminated after completing the recombineering to maintain the engineered genome stable, to remove any marker used to select for the plasmids, and to allow the introduction of other plasmids for next round engineering without any interference with the RecET vector. To convert the plasmid pJB658-recET into a curable RecET vector, the trfA gene responsible for the replication initiation from the RK2 origin of replication was substituted with the temperature-sensitive trfAts gene (Datta et al., 2006; Roberts et al., 1990), constructing plasmid pJB658ts-recET (Table S1). Replication from the RK2 origin in the presence of the trfAts gene has been reported to be stable, less stable (about half), marginal, and absent at $30,33,37$, and $42^{\circ} \mathrm{C}$, respectively (Roberts et al., 1990). Once the recombinant $P$. putida KT2440 strain harboring plasmid pJB658ts-recET was streaked on LB-agar plate without Ap and incubated at $37^{\circ} \mathrm{C}$ to cure the plasmid, four out of 16 randomly selected single colonies were sensitive to Ap, inferring successful curing of the plasmid pJB658ts-recET (Table 1). The non-permissive temperature $42^{\circ} \mathrm{C}$ could not be used to cure the plasmid as the colonies of $P$. putida KT2440 strains did not grow at this temperature. Unexpectedly, switching the plasmid pJB658-recET to the plasmid pJB658ts-recET dramatically dropped the efficiency of the $p v d D$ gene knockout by more than 10 -fold (Fig. 2c). The recombineering efficiency could not be improved even after preparing the 


\section{ACCEPTED MANUSCRIPT}

recombineering competent cells at $\mathrm{OD}_{600}$ above 2 (Fig. 2d).

As the efficiency of the recombineering using the temperature-sensitive plasmid pJB658ts-recET was exceedingly low, a method to cure plasmid pJB658-recET with high recombineering efficiency guaranteed was explored. Surprisingly, streaking the KT2440recET strain harboring plasmid pJB658-recET on LB plate followed by incubation at $37^{\circ} \mathrm{C}$ was enough to cure the plasmid from all 12 colonies randomly selected (Table 1). To examine whether the curing of plasmid pJB658-recET due to an unreported temperature sensitivity of RK2 origin, the recombinant KT2440-recET strain was streaked on LB-agar plate without Ap and incubated at $30^{\circ} \mathrm{C}$, which is a permissive temperature for most temperature-sensitive plasmids. Antibiotic sensitivity analysis on the colonies revealed all 16 colonies randomly selected are sensitive to Ap, inferring instability of the plasmid pJB658-recET rather than temperature sensitivity leads to the plasmid curing (Table 1). Thus, the curable plasmid pJB658-recET was used in the following recombineering experiments.

\subsection{Integration of Cre/lox system for markerless recombineering}

To remove the antibiotic marker inserted into the target chromosomal locus after recombineering, the Cre/lox system was combined to the RecET recombineering system. Briefly, antibiotic markers flanked by mutant lox sites (e.g. lox71 and lox61) (Fig. 3c) and introduced to the chromosome by RecET recombineering system can be easily excised out upon the expression of Cre protein (Palmeros et al., 2000). To construct a Cre vector curable after eliminating the integrated antibiotic marker, plasmid pCreRK2A was constructed by recombining the lacI-cre genes from plasmid pJW168 and the replicon of plasmid pJB658 (Fig. 3a and Table S1), as the plasmid pJB658-recET has been demonstrated to be readily 


\section{ACCEPTED MANUSCRIPT}

curable. In addition, to simplify the preparation of the linear donor dsDNA harboring the antibiotic marker flanked by the mutant lox site, a template plasmid pTetAmulox harboring the lox71-tetA $(C)$-lox66 cassette was constructed so that 100-bp homologies to the recombineering target can be added by extension PCR (Fig. 4a). To examine the Cre/lox system constructed, the $p v d D$ gene of $P$. putida KT2440 was knocked out using a new donor dsDNA $\Delta$ pvdD1k100::tetA-lox (Table S3) amplified from the plasmid pTetAmulox. The resulting mutant $P$. putida KT2440 strain harboring the lox71-tetA(C)-lox66 cassette on the $p v d D$ gene were then transformed with plasmid pCreRK2A and streaked on LB-agar plate supplemented with Ap and IPTG to remove the $\operatorname{tet} A(C)$ gene. Assessment of the Tc sensitivity and the $p v d D$ gene knockout locus indicated that the $\operatorname{tet} A(C)$ gene was successfully eliminated from all 16 colonies randomly selected, demonstrating the efficiency of the Cre/lox system.

Curing of the plasmid pCreRK2A, however, was extremely inefficient in contrary to the curing of plasmid pJB658-recET. Streaking of the mutant strain harboring the plasmid pCreRK2A on LB-agar plate without Ap with subsequent incubation at $30^{\circ} \mathrm{C}$ resulted in only one colony sensitive to Ap out of 54 colonies randomly selected (Table 1). Even after the second round of streaking, no additional colonies cured of plasmid pCreRK2A was found out of 48 colonies derived from three different colonies from the first round streaking (Table 1). The same result was obtained for additional 48 colonies obtained after two rounds of streaking at $37^{\circ} \mathrm{C}$ (Table 1). To construct another Cre vector with high curing efficiency, temperature-sensitive RK2 origin was recombined with the lacI-cre genes from plasmid pJW168 and the Km resistance gene $\operatorname{aph}\left(3^{\prime}\right)-I$ from plasmid pTac15K. The functionality of the resulting plasmid pRK2Cre (Fig. $3 b$ and Table S1) was examined by transforming the 


\section{ACCEPTED MANUSCRIPT}

mutant $P$. putida strain harboring the lox71-tetA(C)-lox66 cassette on the $p v d D$ gene with the plasmid pRK2Cre followed by incubation on LB-agar plate supplemented with IPTG. Assessment of the knockout site on the $p v d D$ gene indicated successful elimination of the tetA $(C)$ gene from 15 out of 16 colonies randomly selected. Subsequent streaking of one random positive mutant on LB-agar plate without antibiotic supplementation followed by incubation at 30 and $37^{\circ} \mathrm{C}$ resulted in 9 and 11 colonies sensitive to $\mathrm{Km}$ out of each of the 16 colonies randomly selected, confirming efficient curing of plasmid pRK2Cre (Table 1).

\subsection{Assessment of the recombineering capacity by gene knockout}

To examine the recombineering capacity of the RecET system developed in this study, multiple genomic loci throughout the chromosome of $P$. putida KT2440 were selected for markerless gene knockout (Fig. 3d). For genomic loci including the $p v d D$ genes, 10 different contiguous regions of which length range from 1 to $70 \mathrm{~kb}$ were successfully knocked out using a series of donor dsDNAs with a pair of 100-bp homology arms (Fig. 4b, S2, and Table 2). Similarly, deletion of two different contiguous regions (69.3 and $101.7 \mathrm{~kb}$ ) around the flagellar gene cluster was demonstrated (Fig. 4b, S2, and Table 2). It should be noted that 1.1 and $1.6 \%(69.3$ and $101.7 \mathrm{~kb}$, respectively) of the chromosomal DNA of $P$. putida $\mathrm{KT} 2440(6181.9 \mathrm{~kb})$ could be deleted by a single round of gene knockout. In addition, four additional loci located throughout the genome of $P$. putida KT2440, including the eda, $e d d, d s b A$, and $z w f$ genes, were successfully knocked out, proving the capacity and the efficiency of the RecET recombineering system (Fig. 4b, S2, and Table 2). Throughout the knockout experiments, the success rates of gene knockout, marker excision, and plasmid curing reached almost $100 \%$ for each colony formed (Table 2). 


\section{ACCEPTED MANUSCRIPT}

The phenotypes of the knockout mutants were subsequently examined to confirm once more the deletion of the selected target genes. As expected, the $p v d D$ mutant $\Delta \mathrm{pvdD} 1 \mathrm{k}$ (Table S1) lost the characteristic green fluorescence of pyoverdine (Fig. 5a and b), the siderophore naturally secreted to the medium by the wild-type KT2440 strain (Joshi et al., 2014), demonstrating the disruption of the pyoverdine biosynthetic pathway. In addition, the two mutants with the flagellar gene clusters deleted ( $\Delta$ flg69.3k and $\Delta$ flg $101.7 \mathrm{k}$ ) exhibited loss of the flagella complex (Fig. 5d-f) thus no motility on $0.3 \% \mathrm{LB}(5 \mathrm{~g} / \mathrm{L} \mathrm{NaCl})$-agar plate (Fig. 5c). These gene knockout experiments and results demonstrate the high recombineering capacity of the RecET recombineering system combined with the Cre/lox system.

\subsection{Establishment of donor plasmid system for markerless integration of BGCs}

With the recombineering capacity of the RecET system in knocking out various regions around the chromosomal DNA of $P$. putida, markerless integration of heterologous biosynthetic genes was undertaken. Compared to the gene knockout that uses 1.8-kb long PCR product as donor DNA for recombineering, heterologous BGCs for valuable natural products are commonly large. For example, the lycopene BGC (crtEIB genes) responsible for converting farnesyl diphosphate to lycopene is $3.5 \mathrm{~kb}$ in size (Choi et al., 2010). More problematic for heterologous integration of the violacein BGC (vioABCDE genes) responsible for converting L-tryptophan to violacein, which is $7.4 \mathrm{~kb}$ in size (Duran et al., 2016). The large size of the natural product BGCs hinders efficient amplification of the donor dsDNA for recombineering, increases the probability of introducing mutations in the amplified product, and reduces the transformation efficiency of the host organism owing to the long length of the dsDNA. To overcome these obstacles, a donor plasmid for the delivery 
of the heterologous BGCs, antibiotic marker, and a pair of homology arms were designed (Fig. 6a and b). Applying this system, large quantity of donor DNA can be easily isolated from recombinant $E$. coli cloning hosts, and the occurrence of mutations on the donor DNA is negligible as the mutation rate in cloning hosts is extremely low comparing to the PCR amplification. Furthermore, the introduction of the donor DNA to the recombineering subject can be maximized, as transformation of bacteria with supercoiled plasmids isolated from the cloning host is extremely efficient. In addition, to combine the laborious two-step processes for inducing and selecting strains that need two rounds of crossover on both homology arms into a single step, the $s a c B$ gene was introduced to the donor plasmid as a negative selection marker. Consequently, with the supplementation of sucrose to the medium, levansucrase expressed from the $s a c B$ gene kills the host strain that experienced only a single crossover event thus harboring the $s a c B$ gene in the chromosome.

As a proof-of-concept, a donor plasmid pTetSac- $\Delta \mathrm{pvdD}$ harboring $\operatorname{lox} 71-\operatorname{tet} A(C)$ lox66 cassette flanked by a pair of 1-kb homology arms, the $s a c B$ gene, and pUC origin of replication with high copy number was constructed (Table S1) and used to knockout the 1-kb region of the $p v d D$ gene. The recombinant KT2440-recET strain induced with $m$-toluic acid was transformed with $1 \mu \mathrm{g}$ of the plasmid pTetSac- $\Delta \mathrm{pvdD}$ and plated on LB-agar plate supplemented with Tc (LB-Tc plate) and LB (0 g/L NaCl)-agar plate supplemented with Tc and $10 \%(w / v)$ sucrose (LB-TcSucrose plate). As a result, 391 and 539 colonies, which are much larger in number than that obtained by transforming with $3 \mathrm{~g}$ of the linear donor dsDNA $\Delta$ pvdD1k100::tetA, were obtained, respectively (Table 2). Subsequent assessment of randomly selected 83 colonies for the replacement of the $1-\mathrm{kb}$ deletion of the $p v d D$ gene with the lox71-tetA $(C)$-lox66 cassette revealed that 82 and 83 colonies from LB-Tc and LB- 


\section{ACCEPTED MANUSCRIPT}

TcSucrose plates, respectively, were engineered as desired. The one colony from the LB-Tc plate of which $p v d D$ gene knockout could not be confirmed was further proved to be susceptible on LB-TcSucrose plate, inferring the occurrence of only a single recombination event with either of the two homology arms of the donor plasmid pTetSac- $\Delta p v d D$ and the presence of the $s a c B$ gene on the chromosome. This infers the negative selection with sucrose facilitates the selection of colonies that experienced double crossover events in a single round of recombineering. These results indicate that the donor plasmid pTetSac- $\Delta p v d D$ is a reliable platform for the single-step recombineering of target genomic locus of $P$. putida.

\subsection{Markerless integration of heterologous BGCs with donor plasmids}

To construct donor plasmids delivering heterologous biosynthetic genes, an adaptor vector pTetSac- $\Delta \mathrm{pvdD}:$ Adaptor harboring a multiple cloning site between the left homology arm and the loc71-tetA $(C)$-lox66 cassette was constructed (Fig. 6a and Table S1). The egfp and rppA gene expression units - both of them are $1.2 \mathrm{~kb}$ in length - responsible for the production of the green fluorescent protein EGFP and the polyketide flaviolin, respectively, were cloned using the adaptor vector (Fig. 6b). In addition, the crtEIB and vioABCDE genes -3.5 and $7.4 \mathrm{~kb}$ in length - responsible for the production of the isoprenoid lycopene and the L-tryptophan-derivative violacein, respectively, were cloned into the plasmid pTetSac$\Delta$ pvdD::Adaptor (Fig. 6b). As a result, donor plasmids pTetSac- $\Delta$ pvdD::EGFP, pTetSac$\Delta$ pvdD::Flaviolin, $\quad$ TetSac- $\Delta$ pvdD::Lycopene, and pTetSac- $\Delta$ pvdD::Violacein were constructed (Table S1). One interesting observation made was that the introduction of the tac promoter without the $l a c O$ and the ribosome binding site on the immediate upstream of the vioA coding sequence (Fig. 6b and Table S1) was enough to impart dark purple color, which 
is the characteristic color of violacein, to the recombinant $E$. coli strain harboring the plasmid pTetSac- $\Delta$ pvdD::Violacein. Considering the start codon of the vioA gene was placed before the transcription start site of the tac promoter, it is speculated that an in-frame ribosome binding site/start codon pair near the 5' end of the vioA gene is present (Fig. 6b).

Recombineering of the recombinant KT2440-recET strain using the donor plasmids pTetSac- $\Delta$ pvdD::EGFP, pTetSac- $\Delta$ pvdD::Flaviolin, and pTetSac- $\Delta$ pvdD::Violacein followed by incubation on $\mathrm{LB}-\mathrm{TcSucrose}$ plates at $30^{\circ} \mathrm{C}$ resulted in weak green fluorescent, weak brown, and dark purple colonies, indicating the production of EGFP, flaviolin, and violacein by the recombinant $P$. putida colonies, respectively. Subsequent assessment of the heterologous gene integration by colony PCR doubly confirmed the successful replacement of the the $1-\mathrm{kb}$ region of the $p v d D$ gene with the egfp $(1.2 \mathrm{~kb}), \operatorname{rpp} A(1.2 \mathrm{~kb})$, or violacein biosynsthetic genes $(7.4 \mathrm{~kb})$ in a significant fraction of colonies formed (Table 3). Although no red colony was found after recombineering with the plasmid pTetSac- $\Delta$ pvdD::Lycopene, most of the colonies (103 out of 120 colonies) harbored the heterologous lycopene biosynthetic gene clusters (Table 3). None of the recombinant colonies harbored the $s a c B$ gene or the replicon of the donor plasmid. Markerless integration of the heterologous genes and clusters was completed by excising out the $\operatorname{tet} A(C)$ gene by introducing the Cre vector pRK2Cre and curing both plasmids pJB658-recET and pRK2Cre with 100\% efficiency (Table 3). The characteristic colors of the heterologous products could be observed in the final recombinant strains with no marker nor plasmid, except for the one harboring the lycopene biosynthetic gene clusters (Fig. 6c).

The markerless recombineering system developed in this study takes as little as five days - one day for introducing the RecET vector, one day for recombineering, two days for 
excising out the integrated marker, and one day for plasmid curing - to modify a single locus on the P. putida chromosome, thus $4 \mathrm{~N}+1$ days to complete $\mathrm{N}$ cycles of iterative engineering. The accuracy, rapidness, and the markerlessness make this system more preferable over the current transposon/marker-based random insertion (3 - 5 days/cycle) (Domrose et al., 2017; Loeschcke et al., 2013; Martinez-Garcia and de Lorenzo, 2012) and homologous recombination-based markerless reombineering (7 - 10 days/cycle) (Cao et al., 2012; Martinez-Garcia and de Lorenzo, 2012) for plasmid-free expression of heterologous BGCs in P. putida. In addition, the performance of the markerless recombineering system is comparable to the latest markerless genome engineering tools of $E$. coli $(3-5$ days/cycle) (Bassalo et al., 2016; Juhas and Ajioka, 2016; Reisch and Prather, 2015). This system with high capacity is expected to become more competitive by adopting latest strategies of recombineering, such as joining of the recombineering vector and the Cre vector (Song and Lee, 2013) and simultaneous engineering of multiple loci (Cho et al., 2017; Jensen et al., 2015), thereby saving additional time per engineering cycle.

\section{Conclusions}

In summary, we developed a RecET recombineering system for engineering of $P$. putida strains expressing heterologous natural product BGCs free of antibiotic marker and plasmid. Using linear donor dsDNA, 16 different contiguous regions on the chromosomal DNA could be knocked out, including the multiple deletion examples including 60, 69.3, 70, and $101.7-\mathrm{kb}$ region (spanning $0.97,1.1,1.1$, and $1.6 \%$ of the $P$. putida KT2440 chromosomal DNA, respectively). In addition, heterologous BGCs, including 7.4-kb violacein BGC, were successfully integrated using the efficient donor plasmid system. With 
the established plasmid curing systems, the recombineering system developed here is evidently capable of iterative recombineering for the extensive engineering of $P$. putida strains (Fig. 3c). The markerless recombineering tool developed in this study will expedite metabolic engineering of $P$. putida for the production of valuable chemicals, including those requiring large heterologous gene clusters.

\section{Acknowledgements}

We thank Dongsoo Yang for fruitful discussion. Plasmid pSIM9 was a kind gift of Dr. Donald L. Court. Plasmid pJB658 was provided by National BioResource Project (NIG, Japan). The work presented in this article is supported by Novo Nordisk Foundation grant NNF16OC0021746. Further support was provided by Technology Development Program to Solve Climate Changes on Systems Metabolic Engineering for Biorefineries (Grants NRF2012M1A2A2026556 and NRF-2012M1A2A2026557) from the Ministry of Science and ICT through the National Research Foundation (NRF) of Korea.

\section{Author contributions}

S.Y.L. conceived the project. K.R.C. designed the experiments. K.R.C. conducted all the experiments and analyzed the data. J.S.C., I.J.C., and D.P. contributed to performing PCR, colony counting, and recombineering. S.Y.L., K.R.C., and J.S.C. wrote the manuscript. All authors read and approved the final manuscript.

\section{Declarations of interest: None}


Appendix A. Supplementary material 


\section{References}

Aparicio, T., de Lorenzo, V., Martinez-Garcia, E., 2017. CRISPR/Cas9-based counterselection boosts recombineering efficiency in Pseudomonas putida. Biotechnol. J. DOI: 10.1002/biot.201700161.

Aparicio, T., Jensen, S.I., Nielsen, A.T., de Lorenzo, V., Martinez-Garcia, E., 2016. The Ssr protein (T1E_1405) from Pseudomonas putida DOT-T1E enables oligonucleotidebased recombineering in platform strain $P$. putida EM42. Biotechnol. J. 11, 1309-1319.

Balzer, S., Kucharova, V., Megerle, J., Lale, R., Brautaset, T., Valla, S., 2013. A comparative analysis of the properties of regulated promoter systems commonly used for recombinant gene expression in Escherichia coli. Microb. Cell Fact. 12, 26.

Bassalo, M.C., Garst, A.D., Halweg-Edwards, A.L., Grau, W.C., Domaille, D.W., Mutalik, V.K., Arkin, A.P., Gill, R.T., 2016. Rapid and efficient one-step metabolic pathway integration in E. coli. ACS Synth. Biol. 5, 561-568.

Blatny, J.M., Brautaset, T., Winther-Larsen, H.C., Karunakaran, P., Valla, S., 1997. Improved broad-host-range RK2 vectors useful for high and low regulated gene expression levels in gram-negative bacteria. Plasmid 38, 35-51.

Cao, L., Wang, Q., Zhang, J., Li, C., Yan, X., Lou, X., Xia, Y., Hong, Q., Li, S., 2012. Construction of a stable genetically engineered rhamnolipid-producing microorganism for remediation of pyrene-contaminated soil. World J. Microbiol. Biotechnol. 28, 2783-2790.

Chai, Y., Shan, S., Weissman, K.J., Hu, S., Zhang, Y., Muller, R., 2012. Heterologous expression and genetic engineering of the tubulysin biosynthetic gene cluster using Red/ET recombineering and inactivation mutagenesis. Chem. Biol. 19, 361-371.

Chen, Z., Ling, W., Shang, G., 2016. Recombineering and I-SceI-mediated Pseudomonas putida KT2440 scarless gene deletion. FEMS Microbiol. Lett. 363, fnw231.

Cho, J.S., Choi, K.R., Prabowo, C.P.S., Shin, J.H., Yang, D., Jang, J., Lee, S.Y., 2017. CRISPR/Cas9-coupled recombineering for metabolic engineering of Corynebacterium glutamicum. Metab. Eng. 42, 157-167.

Choi, H.S., Lee, S.Y., Kim, T.Y., Woo, H.M., 2010. In silico identification of gene amplification targets for improvement of lycopene production. Appl. Environ. Microbiol. 76, 3097-3105.

Cook, T.B., Rand, J.M., Nurani, W., Courtney, D.K., Liu, S.A., Pfleger, B.F., 2018. Genetic tools for reliable gene expression and recombineering in Pseudomonas putida. J. Ind. Microbiol. Biotechnol. DOI: 10.1007/s10295-017-2001-5.

Copeland, N.G., Jenkins, N.A., Court, D.L., 2001. Recombineering: a powerful new tool for mouse functional genomics. Nat. Rev. Genet. 2, 769-779.

Datta, S., Costantino, N., Court, D.L., 2006. A set of recombineering plasmids for gramnegative bacteria. Gene 379, 109-115.

Domrose, A., Klein, A.S., Hage-Hulsmann, J., Thies, S., Svensson, V., Classen, T., Pietruszka, J., Jaeger, K.E., Drepper, T., Loeschcke, A., 2015. Efficient recombinant production of prodigiosin in Pseudomonas putida. Front. Microbiol. 6, 972.

Domrose, A., Weihmann, R., Thies, S., Jaeger, K.E., Drepper, T., Loeschcke, A., 2017. Rapid generation of recombinant Pseudomonas putida secondary metabolite producers using yTREX. Synth. Syst. Biotechnol. 2, 310-319.

Duran, N., Justo, G.Z., Duran, M., Brocchi, M., Cordi, L., Tasic, L., Castro, G.R., Nakazato, 
G., 2016. Advances in Chromobacterium violaceum and properties of violacein-Its main secondary metabolite: A review. Biotechnol. Adv. 34, 1030-1045.

Federal Register, 1982. Appendix E, Certified host-vector systems. Washington, DC 47, 17197.

Galvao, T.C., de Lorenzo, V., 2005. Adaptation of the yeast URA3 selection system to gramnegative bacteria and generation of a $\triangle$ betCDE Pseudomonas putida strain. Appl. Environ. Microbiol. 71, 883-892.

Gibson, D.G., Young, L., Chuang, R.Y., Venter, J.C., Hutchison, C.A., 3rd, Smith, H.O., 2009. Enzymatic assembly of DNA molecules up to several hundred kilobases. Nat. Methods 6, 343-345.

Glandorf, D.C., Verheggen, P., Jansen, T., Jorritsma, J.W., Smit, E., Leeflang, P., Wernars, K., Thomashow, L.S., Laureijs, E., Thomas-Oates, J.E., Bakker, P.A., van Loon, L.C., 2001. Effect of genetically modified Pseudomonas putida WCS358r on the fungal rhizosphere microflora of field-grown wheat. Appl. Environ. Microbiol. 67, 33713378.

Gong, T., Liu, R., Che, Y., Xu, X., Zhao, F., Yu, H., Song, C., Liu, Y., Yang, C., 2016. Engineering Pseudomonas putida KT2440 for simultaneous degradation of carbofuran and chlorpyrifos. Microb. Biotechnol. 9, 792-800.

Graf, N., Altenbuchner, J., 2011. Development of a method for markerless gene deletion in Pseudomonas putida. Appl. Environ. Microbiol. 77, 5549-5552.

Gross, F., Ring, M.W., Perlova, O., Fu, J., Schneider, S., Gerth, K., Kuhlmann, S., Stewart, A.F., Zhang, Y., Muller, R., 2006. Metabolic engineering of Pseudomonas putida for methylmalonyl-CoA biosynthesis to enable complex heterologous secondary metabolite formation. Chem. Biol. 13, 1253-1264.

Ibrahim, S.A., Crack, J.C., Rolfe, M.D., Borrero-de Acuna, J.M., Thomson, A.J., Le Brun, N.E., Schobert, M., Stapleton, M.R., Green, J., 2015. Three Pseudomonas putida FNR family proteins with different sensitivities to $\mathrm{O}_{2}$. J. Biol. Chem. 290, 16812-16823.

Iwasaki, K., Uchiyama, H., Yagi, O., Kurabayashi, T., Ishizuka, K., Takamura, Y., 1994. Transformation of Pseudomonas putida by electroporation. Biosci. Biotechnol. Biochem. 58, 851-854.

Jensen, S.I., Lennen, R.M., Herrgard, M.J., Nielsen, A.T., 2015. Seven gene deletions in seven days: Fast generation of Escherichia coli strains tolerant to acetate and osmotic stress. Sci. Rep. 5, 17874.

Johnson, C.W., Abraham, P.E., Linger, J.G., Khanna, P., Hettich, R.L., Beckham, G.T., 2017. Eliminating a global regulator of carbon catabolite repression enhances the conversion of aromatic lignin monomers to muconate in Pseudomonas putida KT2440. Metab. Eng. Commun. 5, 19-25.

Joshi, H., Dave, R., Venugopalan, V.P., 2014. Pumping iron to keep fit: modulation of siderophore secretion helps efficient aromatic utilization in Pseudomonas putida KT2440. Microbiology 160, 1393-1400.

Juhas, M., Ajioka, J.W., 2016. Lambda Red recombinase-mediated integration of the high molecular weight DNA into the Escherichia coli chromosome. Microb. Cell Fact. 15, 172.

Kim, J.M., Lee, K.H., Lee, S.Y., 2008. Development of a markerless gene knock-out system for Mannheimia succiniciproducens using a temperature-sensitive plasmid. FEMS Microbiol. Lett. 278, 78-85.

Kuhlman, T.E., Cox, E.C., 2010. Site-specific chromosomal integration of large synthetic 
constructs. Nucleic Acids Res. 38, e92.

Lee, S.Y., Kim, H.U., 2015. Systems strategies for developing industrial microbial strains. Nat. Biotechnol. 33, 1061-1072.

Lee, S.Y., Lee, J.W., Song, H., Kim, J.M., Choi, S., Park, J.H., 2008. Recombinant microorganism having an ability of using sucrose as a carbon source. US patent 20110269183.

Leprince, A., Janus, D., de Lorenzo, V., Santos, V.M., 2012. Streamlining of a Pseudomonas putida genome using a combinatorial deletion method based on minitransposon insertion and the Flp-FRT recombination system. Methods Mol. Biol. 813, 249-266.

Lieder, S., Nikel, P.I., de Lorenzo, V., Takors, R., 2015. Genome reduction boosts heterologous gene expression in Pseudomonas putida. Microb. Cell Fact. 14, 23.

Loeschcke, A., Markert, A., Wilhelm, S., Wirtz, A., Rosenau, F., Jaeger, K.E., Drepper, T., 2013. TREX: a universal tool for the transfer and expression of biosynthetic pathways in bacteria. ACS Synth. Biol. 2, 22-33.

Loeschcke, A., Thies, S., 2015. Pseudomonas putida-a versatile host for the production of natural products. Appl. Microbiol. Biotechnol. 99, 6197-6214.

Luo, X., Yang, Y., Ling, W., Zhuang, H., Li, Q., Shang, G., 2016. Pseudomonas putida KT2440 markerless gene deletion using a combination of lambda Red recombineering and Cre/loxP site-specific recombination. FEMS Microbiol. Lett. 363, fnw014.

Martinez-Garcia, E., de Lorenzo, V., 2011. Engineering multiple genomic deletions in Gramnegative bacteria: analysis of the multi-resistant antibiotic profile of Pseudomonas putida KT2440. Environ. Microbiol. 13, 2702-2716.

Martinez-Garcia, E., de Lorenzo, V., 2012. Transposon-based and plasmid-based genetic tools for editing genomes of gram-negative bacteria. Methods Mol. Biol. 813, 267-283.

Martinez-Garcia, E., de Lorenzo, V., 2017. Molecular tools and emerging strategies for deep genetic/genomic refactoring of Pseudomonas. Curr. Opin. Biotechnol. 47, 120-132.

Martinez-Garcia, E., Nikel, P.I., Aparicio, T., de Lorenzo, V., 2014. Pseudomonas 2.0: genetic upgrading of $P$. putida KT2440 as an enhanced host for heterologous gene expression. Microb. Cell Fact. 13, 159.

Nikel, P.I., Chavarria, M., Danchin, A., de Lorenzo, V., 2016. From dirt to industrial applications: Pseudomonas putida as a synthetic biology chassis for hosting harsh biochemical reactions. Curr. Opin. Chem. Biol. 34, 20-29.

Nikel, P.I., Martinez-Garcia, E., de Lorenzo, V., 2014. Biotechnological domestication of pseudomonads using synthetic biology. Nat. Rev. Microbiol. 12, 368-379.

Noirot, P., Kolodner, R.D., 1998. DNA strand invasion promoted by Escherichia coli RecT protein. J. Biol. Chem. 273, 12274-12280.

Palmeros, B., Wild, J., Szybalski, W., Le Borgne, S., Hernandez-Chavez, G., Gosset, G., Valle, F., Bolivar, F., 2000. A family of removable cassettes designed to obtain antibioticresistance-free genomic modifications of Escherichia coli and other bacteria. Gene 247, 255-264.

Poblete-Castro, I., Becker, J., Dohnt, K., dos Santos, V.M., Wittmann, C., 2012. Industrial biotechnology of Pseudomonas putida and related species. Appl. Microbiol. Biotechnol. 93, 2279-2290.

Reisch, C.R., Prather, K.L., 2015. The no-SCAR (Scarless Cas9 Assisted Recombineering) system for genome editing in Escherichia coli. Sci. Rep. 5, 15096.

Ren, J., Lee, H., Yoo, S.M., Yu, M.S., Park, H., Na, D., 2017. Combined chemical and physical transformation method with $\mathrm{RbCl}$ and sepiolite for the transformation of 
various bacterial species. J. Microbiol. Methods 135, 48-51.

Roberts, R.C., Burioni, R., Helinski, D.R., 1990. Genetic characterization of the stabilizing functions of a region of broad-host-range plasmid RK2. J. Bacteriol. 172, 6204-6216.

Ruan, Y., Zhu, L., Li, Q., 2015. Improving the electro-transformation efficiency of Corynebacterium glutamicum by weakening its cell wall and increasing the cytoplasmic membrane fluidity. Biotechnol. Lett. 37, 2445-2452.

Rybalchenko, N., Golub, E.I., Bi, B., Radding, C.M., 2004. Strand invasion promoted by recombination protein beta of coliphage lambda. Proc. Natl. Acad. Sci. U. S. A. 101, 17056-17060.

Song, C.W., Lee, S.Y., 2013. Rapid one-step inactivation of single or multiple genes in Escherichia coli. Biotechnol. J. 8, 776-784.

Sun, J., Wang, Q., Jiang, Y., Wen, Z., Yang, L., Wu, J., Yang, S., 2018. Genome editing and transcriptional repression in Pseudomonas putida KT2440 via the type II CRISPR system. Microb. Cell Fact. 17, 41.

Tu, Q., Yin, J., Fu, J., Herrmann, J., Li, Y., Yin, Y., Stewart, A.F., Muller, R., Zhang, Y., 2016. Room temperature electrocompetent bacterial cells improve DNA transformation and recombineering efficiency. Sci. Rep. 6, 24648.

Wenzel, S.C., Gross, F., Zhang, Y., Fu, J., Stewart, A.F., Muller, R., 2005. Heterologous expression of a myxobacterial natural products assembly line in pseudomonads via Red/ET recombineering. Chem. Biol. 12, 349-356.

Wild, J., Sektas, M., Hradecna, Z., Szybalski, W., 1998. Targeting and retrofitting pre-existing libraries of transposon insertions with FRT and oriV elements for in-vivo generation of large quantities of any genomic fragment. Gene 223, 55-66. 
Fig. 1. Expression of the RecE and RecT proteins in recombinant $P$. putida strains harboring recombineering vectors. (a) Vector map of plasmid pJB658-recET. (b) Vector map of plasmid pJB658-recTE. (c) Expression of RecE and RecT in P. putida KT2440 harboring the RecET vectors upon induction with $m$-toluic acid ( $m$-TA). Numbers on each lane indicate the concentration of $m$-TA (in $\mathrm{mM}$ ) used for induction. Expected sizes of the $\operatorname{RecE}(\triangleleft)$ and $\operatorname{RecT}(\triangleleft)$ proteins are 96.4 and $29.7 \mathrm{kDa}$, respectively. M, marker.

Fig. 2. Examination of different parameters to improve the recombineering efficiency. (a) Recombineering of KT2440-recET using the cells harvested at $\mathrm{OD}_{600}=0.8,1.4$, and 2.0 and linear donor dsDNA $\triangle$ pvdD::tetA. The transformants were recovered at $30^{\circ} \mathrm{C}$ after electroporation. (b) Recombineering of KT2440-recET strain using the cells harvested at $\mathrm{OD}_{600}=2.0$ and the linear donor dsDNA $\Delta \mathrm{pvdD}:$ :tetA. The transformants were recovered at either 30 or $37^{\circ} \mathrm{C}$ after electroporation. (c) Recombineering of KT2440-recET and KT2440recETts strains harboring plasmids pJB658-recET and pJB658-recETts, respectively, using the cells harvested at $\mathrm{OD}_{600}=2.0$ and the linear donor dsDNAs $\Delta \mathrm{pvdD}$ ::tetA $(\operatorname{tet} A(C))$ or $\Delta$ pvdD::aph (aph(3')-IIa). The transformants were recovered at $30^{\circ} \mathrm{C}$ after electroporation. (d) Recombineering of KT2440-recETts strain using the cells harvested at $\mathrm{OD}_{600}=2.2,2.7$, and 32. Linear donor dsDNA $\Delta$ pvdD::tetA was used. The transformants were recovered at either 30 or $37^{\circ} \mathrm{C}$ after electroporation. All recombinant $P$. putida strains were induced with $5 \mathrm{mM}$ $m$-toluic acid. The cell density of all competent cells were normalized before use. Knockout of the $p v d D$ gene were confirmed in all colonies formed. All data are mean value of biological triplicates. Error bars represent standard deviations. NS, not significant, ${ }^{*}, p<0.05$, 
**, $p<0.01$, determined by Student's $t$-test.

Fig. 3. Construction of markerless recombineering system by integrating the Cre/lox system. (a) Vector map of plasmid pCreRK2A. (b) Vector map of plasmid pCreRK2. (c) Structure of $\operatorname{tet} A(C)$ cassette flanked by mutant lox sites lox71 and lox66. (d) Overall scheme of markerless recombineering in $P$. putida. Plasmid pJB658-recET harboring the recET genes is introduced to $P$. putida cells (1) and induced with $5 \mathrm{mM} m$-toluic acid, followed by transformation with donor DNA in the form of either linear dsDNA or plasmid (2). Cells are plated on tetractcline (Tc) plates and positive mutants are selected. Ampicillin (Ap) may be added to the plate to maintain the plasmid pJB658-recET at higher frequency. To excise out the $\operatorname{tet} A(C)$ cassette, the Tc-resistant cells are transformed with plasmid pRK2Cre (3) and plated on either kanamycin $(\mathrm{Km})$-Ap plate or $\mathrm{Km}$ plate to obtain intermediate strain for next round recombineering (4-1) or final recombinant strain without marker and plasmid (4-2). To obtain the intermediate strain for further recombineering, Tc-sensitive colonies from the KmAp plate are streaked on an Ap plate and incubated at $37^{\circ} \mathrm{C}$ to cure plasmid $\mathrm{pRK} 2 \mathrm{Cre}$ while maintaining plasmid pJB658-recET (5-1). The resulting strain may undergo next round recombineering (2). To generate the final recombinant strain, Tc-sensitive colonies from the $\mathrm{Km}$ plate are further streaked on a plate without any antibiotic and incubated at $37^{\circ} \mathrm{C}$ to cure both plasmids pJB658-recET and pRK2Cre (5-2).

Fig. 4. Markerless gene knockout in P. putida. (a) Overall scheme of linear donor dsDNA preparation. The $\Delta^{*} 100:$ :tetA-lox series harboring $\operatorname{tet} A(c)$ gene and mutant lox sites (lox71 and lox66) are amplified from plasmid pTetAmulox through extension PCR. Homologies to 
the flanking regions of deletion targets (100 bp each) are introduced by primers. (b) Chromosomal regions of $P$. putida KT2440 examined for deletion by the markerless gene knockout strategy.

Fig. 5. Phenotypes of gene knockout mutants. (a), (b) Wild-type P. putida KT2440 (left) and the $p v d D$ mutant $\Delta$ pvdD1k (right) under the visible light (a) and UV light (b). (c) Motility of wild-type $P$. putida KT2440 (top) and the flagellar gene cluster knockout mutants $\Delta$ flg69.3k (bottom left) and $\Delta$ flg101.7k (bottom right) on $0.3 \% \mathrm{LB}(5 \mathrm{~g} / \mathrm{L} \mathrm{NaCl})$-agar plate. Overnight liquid cultures of each strain in LB $(5 \mathrm{~g} / \mathrm{L})$ were inoculated and incubated at $30^{\circ} \mathrm{C}$. (d), (e), (f) Scanning electron micrographs of wild-type P. putida KT2440 (d) and the flagellar gene cluster knockout mutants $\Delta$ flg69.3k (e) and $\Delta$ flg101.7k (f). Overnight liquid culture of each strain in LB $(5 \mathrm{~g} / \mathrm{L})$ were washed twice and resuspended with deionized water. The cell suspension was dried on silicon wafer and coated with osmium before observation. Scale bars represent $1 \mu \mathrm{m}$.

Fig. 6. Markerless integration of heterologous genes and clusters. (a) Vector map of plasmid pTetSac- $\Delta$ pvdD::Adaptor. (b) Scheme of constructing donor plasmids harboring the heterologous genes and clusters. White semicircles between the promoter and the first gene represent ribosome binding sites. The semicircle with dashed line on the vioA gene represents a possible ribosome binding site (RBS?). The middle of the vioB gene was not represented due to its long length. (c) Colors of recombinant $P$. putida strains harboring the heterologous biosynthetic genes and clusters $(\Delta \mathrm{pvdD}:$ EGFP, $\Delta \mathrm{pvdD}:$ Flaviolin, $\Delta \mathrm{pvdD}::$ Lycopene, and $\Delta$ pvdD::Violacein) and their control strain $\Delta$ pvdD1k. Expected colors of EGFP, flaviolin, 
lycopene, and violacein are green, brown, red, and purple, respectively. MCS, multiple cloning site.

a

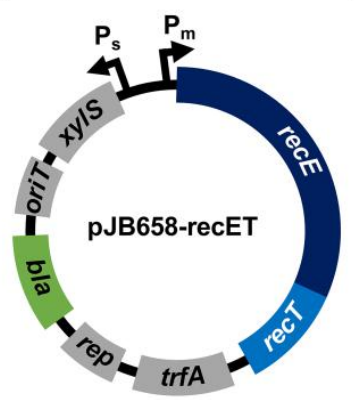

b

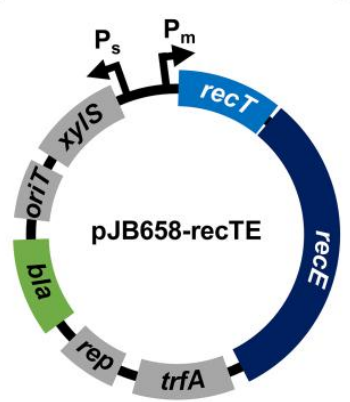

C Pseudomonas putida KT2440

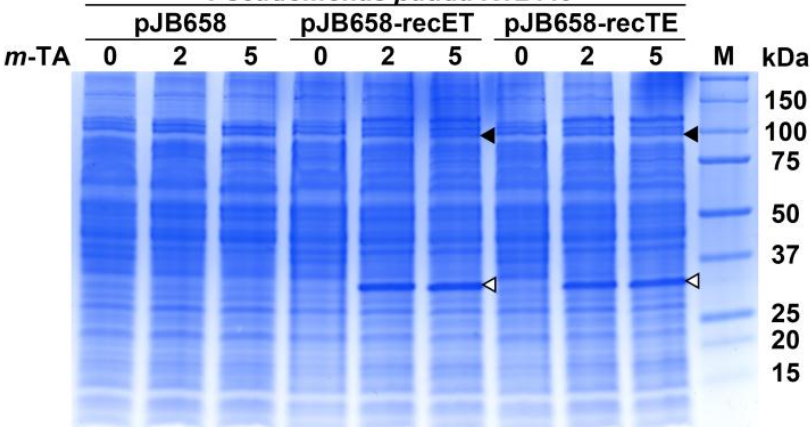

b

d

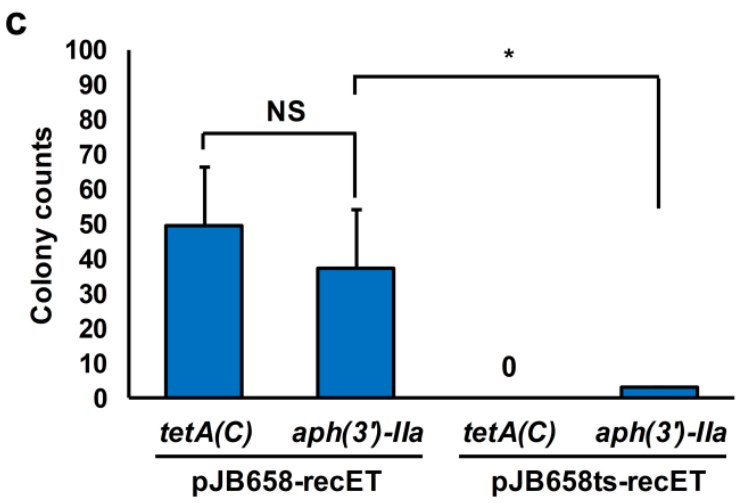

a

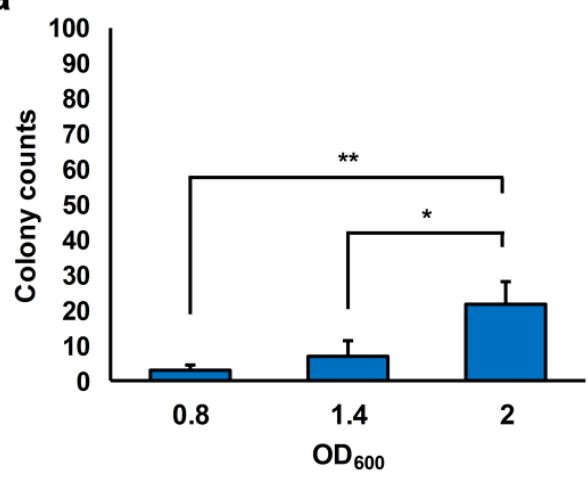

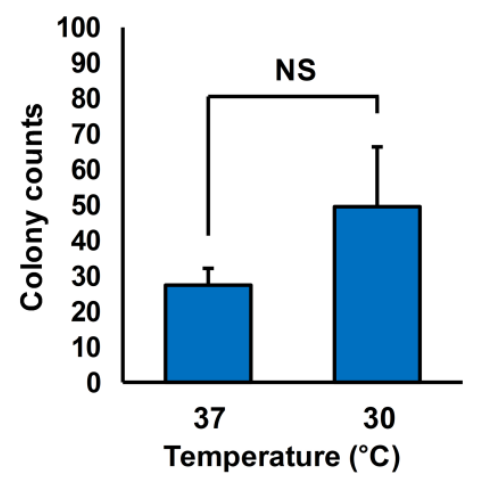

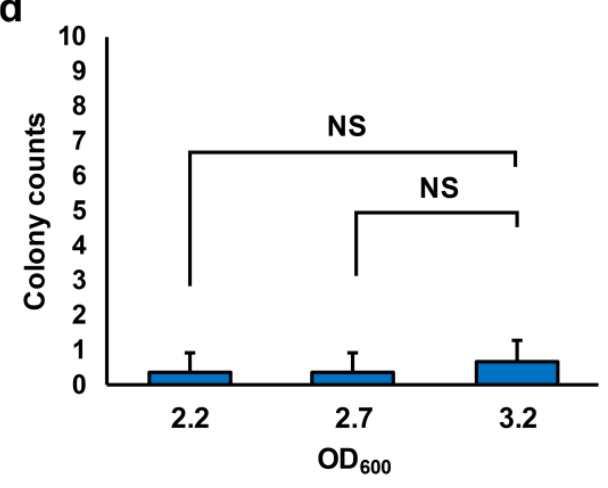




\section{ACCEPTED MANUSCRIPT}

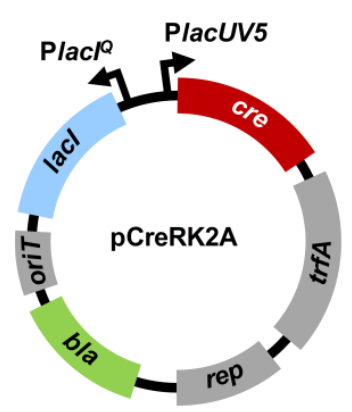

b

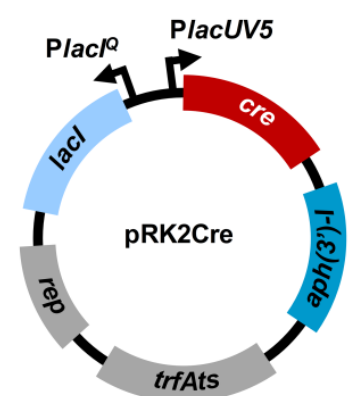

C

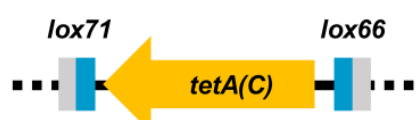

Recombinant strain without

marker \& plasmid
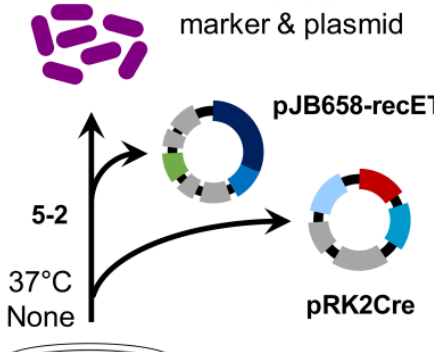
$\mathrm{Km}, \mathrm{Ap}$ Engineering host

pRK2Cre

Donor DNA

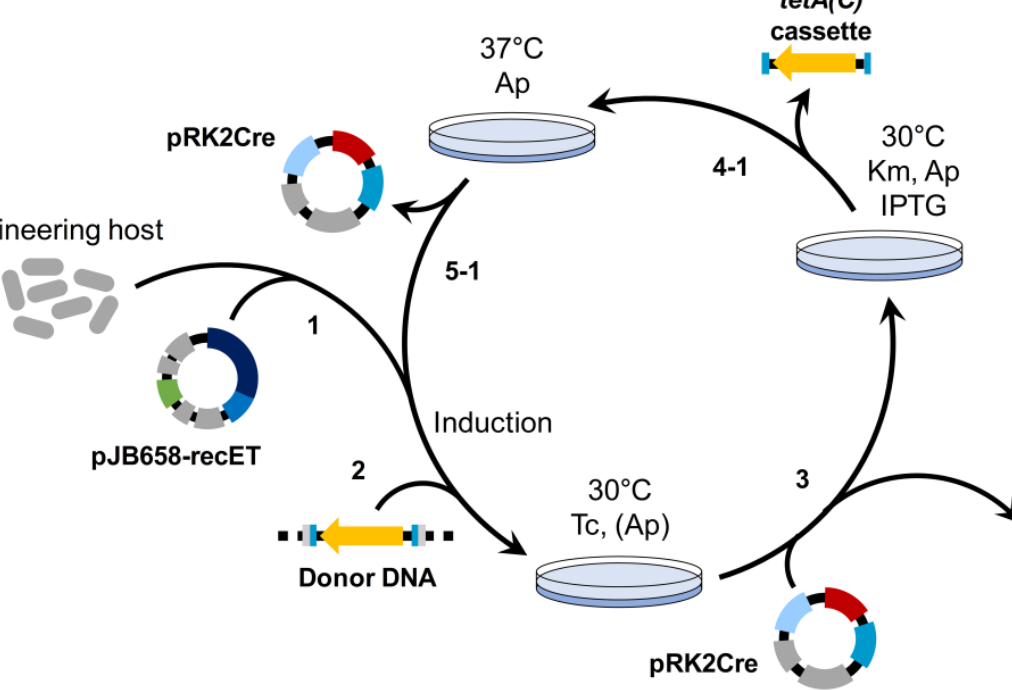

Tc, (Ap)

pRK2Cre
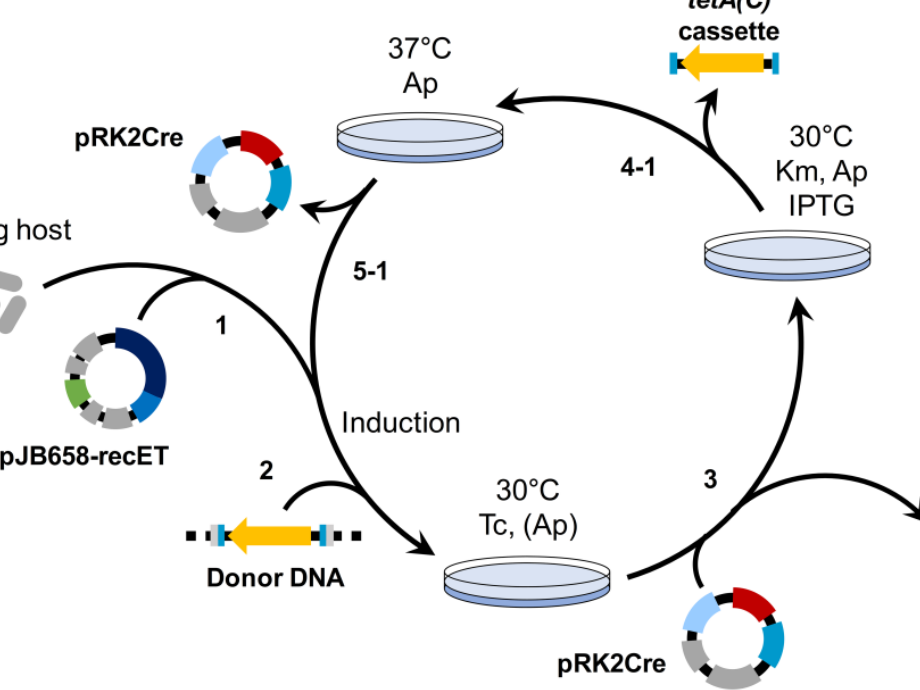

$\operatorname{tet} A(C)$ cassette

d

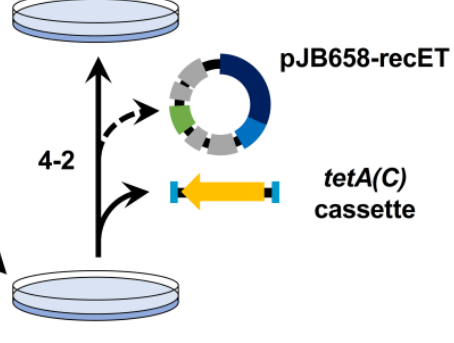

$30^{\circ} \mathrm{C}$

$\mathrm{Km}$, IPTG 


\section{ACCEPTED MANUSCRIPT}
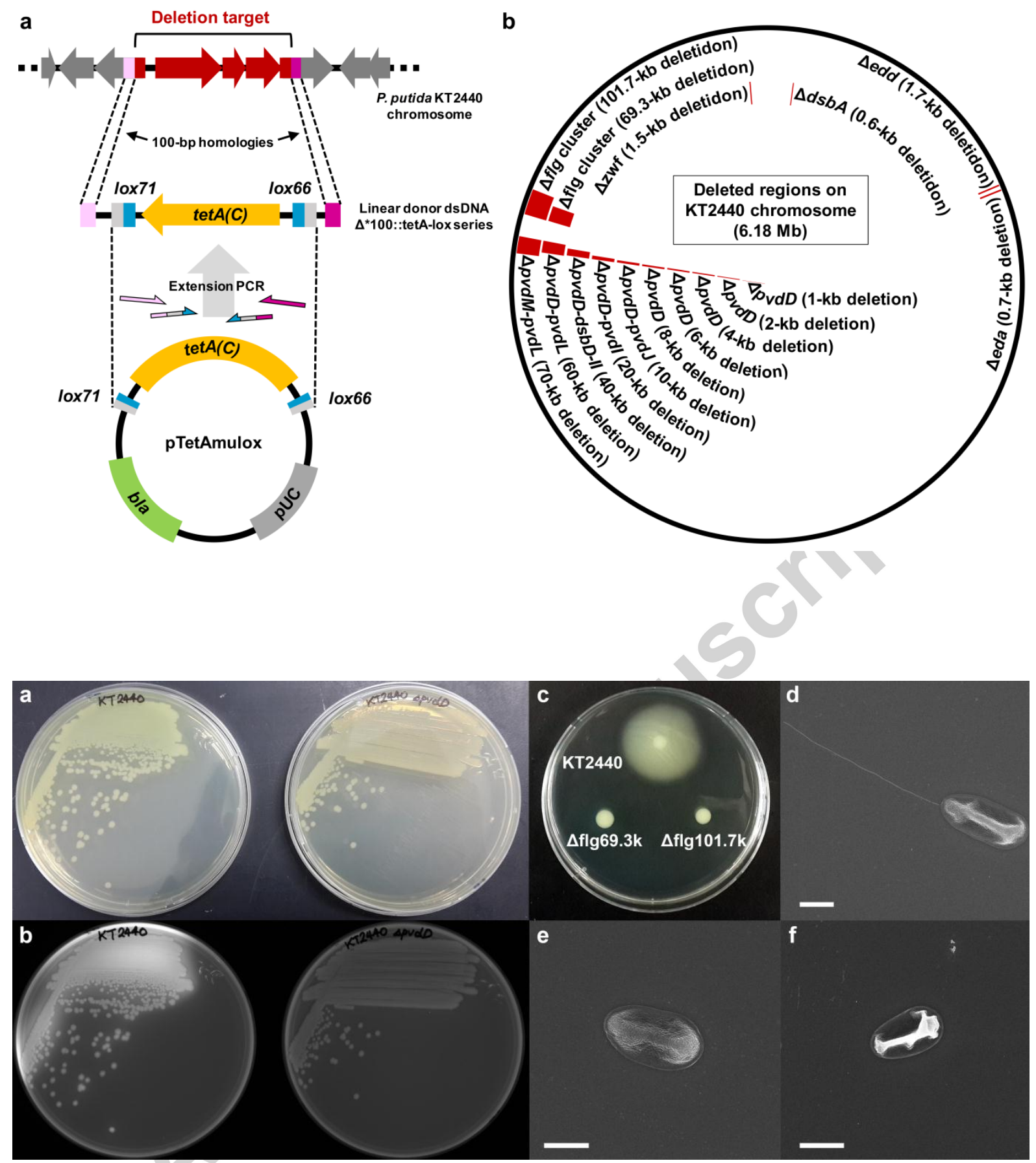


\section{ACCEPTED MANUSCRIPT}

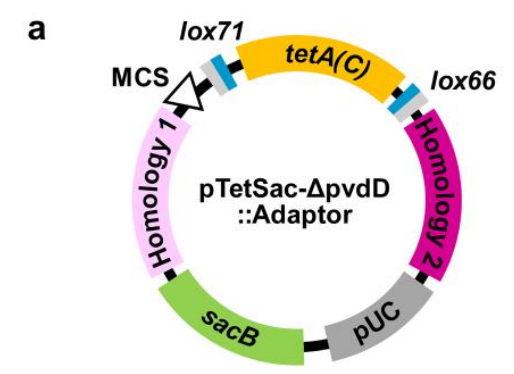

b
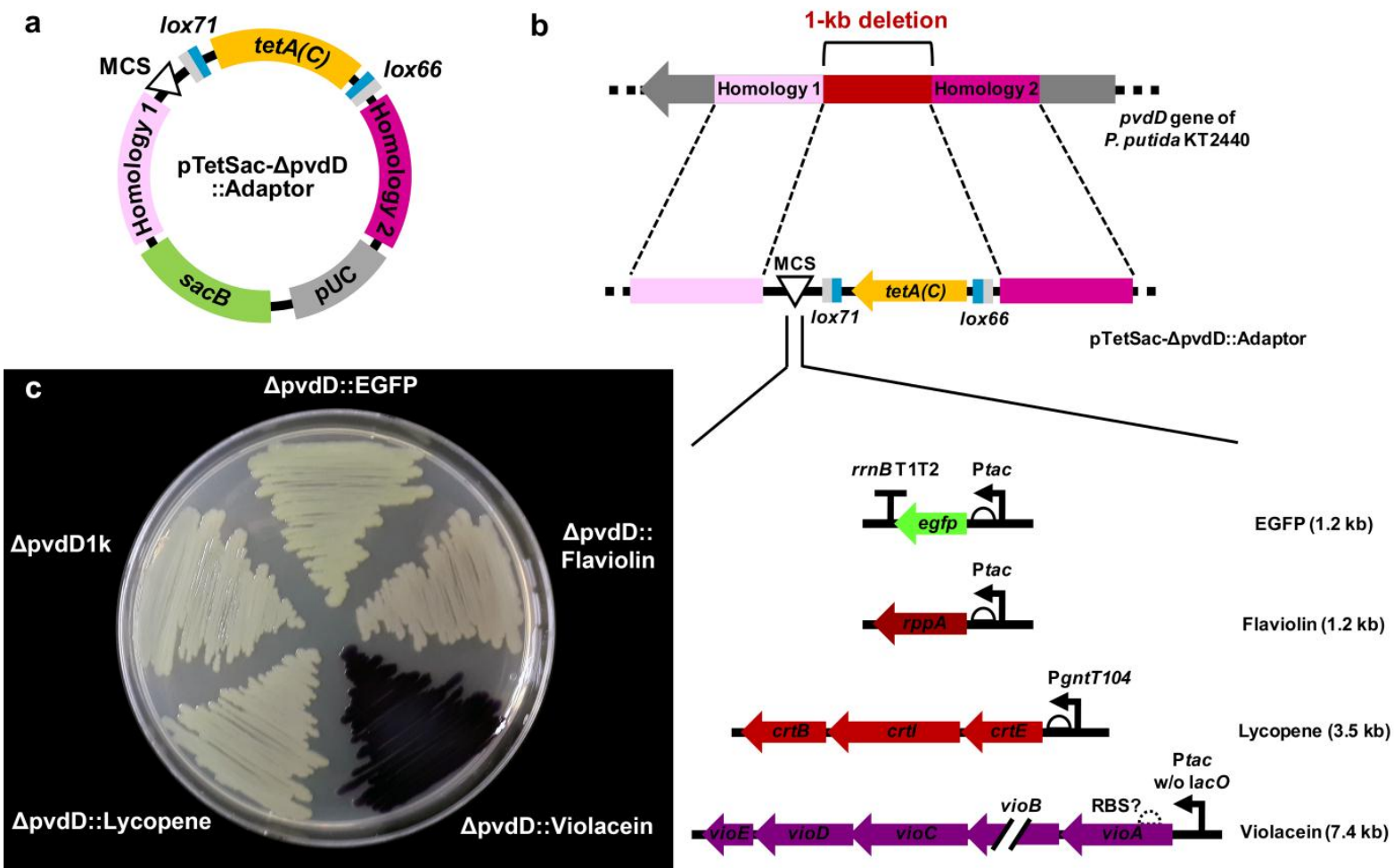


\section{ACCEPTED MANUSCRIPT}

Table 1. Plasmid curing efficiencies of RecET and Cre vectors ${ }^{a}$

\begin{tabular}{|c|c|c|c|c|c|c|c|c|}
\hline \multirow{3}{*}{ Plasmid } & \multicolumn{4}{|c|}{$30^{\circ} \mathrm{C}$ incubation $^{\mathrm{b}}$} & \multicolumn{4}{|c|}{$37^{\circ} \mathrm{C}$ incubation $^{\mathrm{b}}$} \\
\hline & \multirow{2}{*}{$1^{\text {st }}$ round } & \multicolumn{3}{|c|}{$2^{\text {nd }}$ round } & \multirow{2}{*}{$1^{\text {st }}$ round } & \multicolumn{3}{|c|}{$2^{\text {nd }}$ round } \\
\hline & & 1 & 2 & 3 & & 1 & 2 & 3 \\
\hline pJB658-recET & $\begin{array}{l}16 / 16 \\
(100)\end{array}$ & - & - & - & $\begin{array}{l}12 / 12 \\
(100)\end{array}$ & - & - & - \\
\hline pJB658ts-recET & - & - & - & - & $\begin{array}{l}4 / 16 \\
(25)\end{array}$ & - & - & - \\
\hline pCreRK2A & $\begin{array}{c}1 / 54 \\
(1.85)\end{array}$ & $\begin{array}{c}0 / 16 \\
(0)\end{array}$ & $\begin{array}{c}0 / 16 \\
(0)\end{array}$ & $\begin{array}{c}0 / 16 \\
(0)\end{array}$ & - & $\begin{array}{c}0 / 16 \\
(0)\end{array}$ & $\begin{array}{l}0 / 16 \\
(0)\end{array}$ & $\begin{array}{r}0 / 16 \\
(0)\end{array}$ \\
\hline pRK2Cre & $\begin{array}{c}9 / 16 \\
(56.25)\end{array}$ & - & - & - & $\begin{array}{c}11 / 16 \\
(68.75)\end{array}$ & & & - \\
\hline
\end{tabular}

a-, not determined

${ }^{\mathrm{b}}$ Number of colonies cured of the plasmid/number of colonies examined (\% efficiency) 
Table 2. Results of markerless gene knockout experiments in $P$. putida KT2440 using RecET recombineering and Cre/lox systems.

\begin{tabular}{|c|c|c|c|c|c|c|c|c|}
\hline \multirow[b]{2}{*}{ Trial } & \multirow[b]{2}{*}{$\begin{array}{l}\text { Target } \\
\text { (length) }\end{array}$} & \multirow[b]{2}{*}{ Donor DNA } & \multicolumn{2}{|c|}{ Knockout efficiency } & \multirow{2}{*}{$\begin{array}{c}\text { Marker } \\
\text { excision } \\
\text { efficiency }\end{array}$} & \multicolumn{3}{|c|}{ Plasmid curing efficiency $^{\mathrm{a}}$} \\
\hline & & & $\begin{array}{c}\text { Total } \\
\text { colony }\end{array}$ & Efficiency $^{\mathrm{a}}$ & & pJB658-recET & pRK2Cre & Both \\
\hline 1 & \multirow{3}{*}{$\begin{array}{l}p v d D \\
(1 \mathrm{~kb})\end{array}$} & \multirow{3}{*}{$\begin{array}{c}\Delta \mathrm{pvdD} 1 \mathrm{k} 100:: \\
\text { tetA-lox }\end{array}$} & 28 & $28 / 28(100)$ & \multirow{3}{*}{-} & \multirow{3}{*}{ - } & \multirow{3}{*}{-} & \multirow{3}{*}{ - } \\
\hline 2 & & & 28 & $28 / 28(100)$ & & & & \\
\hline 3 & & & 16 & $16 / 16(100)$ & & & & \\
\hline 4 & \multirow{3}{*}{$\begin{array}{l}p v d D \\
(2 \mathrm{~kb})\end{array}$} & \multirow{3}{*}{$\begin{array}{c}\Delta \mathrm{pvdD} 2 \mathrm{k} 100:: \\
\text { tetA-lox }\end{array}$} & 4 & $4 / 4(100)$ & \multirow{3}{*}{$\begin{array}{l}10 / 10 \\
(100)\end{array}$} & \multirow{3}{*}{$\begin{array}{l}10 / 10 \\
(100)\end{array}$} & \multirow{3}{*}{$\begin{array}{l}10 / 10 \\
(100)\end{array}$} & \multirow{3}{*}{$\begin{array}{l}10 / 10 \\
(100)\end{array}$} \\
\hline 5 & & & 2 & $2 / 2(100)$ & & & & \\
\hline 6 & & & 4 & $4 / 4(100)$ & & & & \\
\hline 7 & \multirow{3}{*}{$\begin{array}{l}p v d D \\
(4 \mathrm{~kb})\end{array}$} & \multirow{3}{*}{$\begin{array}{c}\Delta \mathrm{pvdD} 4 \mathrm{k} 100:: \\
\text { tetA-lox }\end{array}$} & 3 & $3 / 3(100)$ & \multirow{3}{*}{$\begin{array}{l}10 / 10 \\
(100)\end{array}$} & \multirow{3}{*}{$\begin{array}{l}10 / 10 \\
(100)\end{array}$} & & \\
\hline 8 & & & 2 & $2 / 2(100)$ & & & & $\begin{array}{l}10 / 10 \\
(100)\end{array}$ \\
\hline 9 & & & 2 & $2 / 2(100)$ & & & & \\
\hline 10 & & & 0 & - & & & & \\
\hline 11 & pvan & $\Delta$ pvaDoK I00:: & 3 & 2/3 (66.7) & & $\begin{array}{l}10 / 10 \\
(100)\end{array}$ & & $\begin{array}{l}10 / 10 \\
(100)\end{array}$ \\
\hline 12 & (6 Kb) & tetA-lox & 3 & $2 / 3(66.7)$ & & & & \\
\hline 13 & & & 5 & $5 / 5(100)$ & & & & \\
\hline 14 & pvad & $\Delta$ pvaD8ki00:: & 4 & $4 / 4(100)$ & $10 / 10$ & $10 / 10$ & $10 / 10$ & $10 / 10$ \\
\hline 15 & (8 kb) & tetA-lox & 8 & $8 / 8(100)$ & $(100)$ & $(100)$ & $(100)$ & $(100)$ \\
\hline 16 & & & 1 & $1 / 1(100)$ & & & & \\
\hline 17 & $p v d D-p v d J$ & $\Delta$ pvdDI0K 100 & 2 & $2 / 2(100)$ & $10 / 10$ & $10 / 10$ & $10 / 10$ & $10 / 10$ \\
\hline 18 & (10 kb) & ::tetA-lox & 4 & $4 / 4(100)$ & (100) & (100) & (100) & (100) \\
\hline 19 & & $\Delta \mathrm{pvdD} 20 \mathrm{k} 100$ & 0 & - & $10 / 10$ & $10 / 10$ & $10 / 10$ & $10 / 10$ \\
\hline 20 & pvaD-pvas & $\begin{array}{l}\Delta p v 00 \angle 0 K 100 \\
\text {..tetA-lox }\end{array}$ & 4 & 4/4 (100) & $(100)$ & $(100)$ & $(100)$ & $(100)$ \\
\hline 21 & $(2 \mathrm{U} \mathrm{KD})$ & ...tetA-10x & 1 & $1 / 1(100)$ & & & & \\
\hline 22 & $p v d D$ & & 1 & $1 / 1(100)$ & $10 / 10$ & & & \\
\hline 23 & $d s b D-I I$ & $\begin{array}{l}\Delta \text { pvdD40K } 100 \\
\text {..tetA-lox }\end{array}$ & 1 & $1 / 1(100)$ & $(100)$ & $(100)$ & $(100)$ & $10 / 10$ \\
\hline 24 & $(40 \mathrm{~kb})$ & ..tetA-IOx & 2 & $2 / 2(100)$ & & & & \\
\hline 25 & $p v d D-p v d L$ & $\Delta$ pvdD60k100 & 0 & & $10 / 10$ & $10 / 10$ & $10 / 10$ & $10 / 10$ \\
\hline $\begin{array}{l}26 \\
27\end{array}$ & $(60 \mathrm{~kb})$ & ::tetA-lox & $\begin{array}{l}0 \\
2\end{array}$ & $2 / 2(100)$ & $(100)$ & $(100)$ & $(100)$ & $(100)$ \\
\hline 28 & $p v d M-$ & & 0 & & & & & \\
\hline 29 & $p v d L$ & $\triangle$ pvaD/OKIOU & 1 & 1/1 (100) & $\begin{array}{l}10 / 10 \\
(100)\end{array}$ & $\begin{array}{l}10 / 10 \\
(100)\end{array}$ & $\begin{array}{l}10 / 10 \\
(100)\end{array}$ & $\begin{array}{l}10 / 10 \\
(100)\end{array}$ \\
\hline 30 & $(70 \mathrm{~kb})$ & ..tetA-10X & 1 & $1 / 1(100)$ & & & & \\
\hline 31 & & k100 - k & 1 & 1/1 (100) & & & & \\
\hline 32 & Jlg ciuster & $\begin{array}{c}\Delta \text { mg09.3K } 100 \\
\text { :tetA-lox }\end{array}$ & 3 & $3 / 3(100)$ & $10 / 10$ & $10 t$ & $\begin{array}{l}10 / 10 \\
(100)\end{array}$ & $10 / 10$ \\
\hline 33 & & & 5 & $5 / 5(100)$ & $(100)$ & $(10$ & $(100)$ & $(100)$ \\
\hline & flg cluster & $\Delta$ flg101.7k100 & & & $10 / 10$ & $20 / 20$ & $20 / 20$ & $20 / 20$ \\
\hline 34 & $(101.7 \mathrm{~kb})$ & ::tetA-lox & 6 & $6 / 6(100$ & $(100)$ & $(100)$ & $(100)$ & (100) \\
\hline 35 & $e d a$ & $\Delta$ eda100::tetA & 1 & $1 / 1(100)$ & $10 / 10$ & $10 / 10$ & $10 / 10$ & $10 / 10$ \\
\hline 35 & $(0.7 \mathrm{~kb})$ & $-\operatorname{lox}$ & 1 & $1 / 1(100$ & $(100)$ & $(100)$ & $(100)$ & $(100)$ \\
\hline 36 & $e d d$ & $\Delta$ edd100::tetA & 3 & $3 / 3(100)$ & $10 / 10$ & $10 / 10$ & $10 / 10$ & $10 / 10$ \\
\hline 30 & $(1.7 \mathrm{~kb})$ & $-\operatorname{lox}$ & 3 & $3 / 3(100)$ & $(100)$ & (100) & (100) & (100) \\
\hline 37 & $d s b A$ & $\Delta$ dsbA100::tet & 20 & $20 / 20(100$ & $10 / 10$ & $10 / 10$ & $10 / 10$ & $10 / 10$ \\
\hline 31 & $(0.6 \mathrm{~kb})$ & A-lox & 20 & $20 / 20(100)$ & $(100)$ & $(100)$ & $(100)$ & (100) \\
\hline 38 & $z w f$ & $\Delta$ zwf100::tetA & 6 & & $10 / 10$ & $10 / 10$ & $10 / 10$ & $10 / 10$ \\
\hline 38 & $(1.5 \mathrm{~kb})$ & $-\operatorname{lox}$ & 0 & $6 / 0(10$ & $(100)$ & (100) & $(100)$ & (100) \\
\hline 39 & $p v d D$ & pTetSac- & 391 & $82 / 83(98.8)$ & & & & - \\
\hline 40 & $(1 \mathrm{~kb})$ & $\Delta \mathrm{pvdD}$ & $539^{\mathrm{b}}$ & $83 / 83(100)$ & - & - & - & \\
\hline
\end{tabular}

${ }^{a}$ Number of colonies confirmed/number of colonies examined (\% efficiency); -, not applicable or not determined

${ }^{\mathrm{b}}$ Transformants were plated on LB-TcSucrose plate 
Table 3. Markerless integration of heterologous biosynthetic genes into the $p v d D$ gene of P. putida KT2440.

\begin{tabular}{|c|c|c|c|c|c|c|c|c|}
\hline \multirow[b]{2}{*}{ Trial } & \multirow{2}{*}{$\begin{array}{l}\text { Heterologous } \\
\text { gene } \\
\text { /cluster } \\
\text { (size) }\end{array}$} & \multirow[b]{2}{*}{ Donor DNA } & \multicolumn{2}{|c|}{ Knockout efficiency } & \multirow{2}{*}{$\begin{array}{c}\text { Marker } \\
\text { excision } \\
\text { efficiency }^{\mathrm{a}}\end{array}$} & \multicolumn{3}{|c|}{ Plasmid curing accuracy ${ }^{\mathrm{a}}$} \\
\hline & & & $\begin{array}{l}\text { Total } \\
\text { colony }\end{array}$ & Efficiency $^{\mathrm{a}}$ & & pJB658-recET & pRK2Cre & Both \\
\hline \multirow{2}{*}{1} & $e g f p$ & pTetSac- & \multirow{2}{*}{39} & $29 / 39$ & $10 / 10$ & $10 / 10$ & $10 / 10$ & $10 / 10$ \\
\hline & $(1.2 \mathrm{~kb})$ & $\Delta$ pvdD::EGFP & & $(74.4)$ & $(100)$ & $(100)$ & $(100)$ & $(100)$ \\
\hline \multirow{2}{*}{2} & rрpA & pTetSac- & \multirow{2}{*}{32} & $25 / 32$ & $10 / 10$ & $10 / 10$ & $10 / 10$ & $10 / 10$ \\
\hline & $(1.2 \mathrm{~kb})$ & $\Delta$ pvdD::Flaviolin & & $(78.1)$ & $(100)$ & $(100)$ & $(100)$ & $(100)$ \\
\hline \multirow{2}{*}{3} & Lycopene & pTetSac- & \multirow{2}{*}{120} & $103 / 120$ & $10 / 10$ & $10 / 10$ & $10 / 10$ & $10 / 10$ \\
\hline & $(3.6 \mathrm{~kb})$ & $\Delta$ pvdD::Lycopene & & $(85.8)$ & $(100)$ & $(100)$ & $(100)$ & $(100)$ \\
\hline \multirow{2}{*}{4} & Violacein & pTetSac- & \multirow{2}{*}{46} & $5 / 46$ & $10 / 10$ & $10 / 10$ & $10 / 10$ & $10 / 10$ \\
\hline & $(7.4 \mathrm{~kb})$ & $\Delta$ pvdD::Violacein & & $(10.7)$ & $(100)$ & $(100)$ & $(100)$ & $(100)$ \\
\hline
\end{tabular}

${ }^{a}$ Number of colonies confirmed/number of colonies examined (\% efficiency); -, not applicable or not determined 


\section{Highlights}

- RecET system for markerless recombineering of $P$. putida was constructed.

- Curing systems for RecET and Cre vectors were developed.

- Large region of chromosome up to $101.7 \mathrm{~kb}$ could be deleted.

- A single-step recombineering system was developed using a donor plasmid.

- Violacein biosynthetic gene cluster could be markerlessly integrated. 